NBER WORKING PAPER SERIES

FAMILY VALUES AND THE REGULATION OF LABOR

Alberto F. Alesina

Yann Algan

Pierre Cahuc

Paola Giuliano

Working Paper 15747

http://www.nber.org/papers/w15747

\author{
NATIONAL BUREAU OF ECONOMIC RESEARCH \\ 1050 Massachusetts Avenue \\ Cambridge, MA 02138 \\ February 2010
}

We thank Murat Iyigun and seminar participants at Bocconi University, Brown University, Harvard University, the Kaler meeting at UCLA, IZA, IIES (Stockholm), the London School of Economics, Harvard University, New York University, Princeton University, the Terry College of Business, UC Berkeley Haas School of Business, University of Mannheim, University of Southern California, the AEA Meetings (Denver), the CEPR Conference on Culture and Institutions in Milan and the Politics, Information and the Macroeconomy conference in Barcelona for helpful comments. The views expressed herein are those of the authors and do not necessarily reflect the views of the National Bureau of Economic Research.

NBER working papers are circulated for discussion and comment purposes. They have not been peerreviewed or been subject to the review by the NBER Board of Directors that accompanies official NBER publications.

(C) 2010 by Alberto F. Alesina, Yann Algan, Pierre Cahuc, and Paola Giuliano. All rights reserved. Short sections of text, not to exceed two paragraphs, may be quoted without explicit permission provided that full credit, including $(\mathcal{C}$ notice, is given to the source. 
Family Values and the Regulation of Labor

Alberto F. Alesina, Yann Algan, Pierre Cahuc, and Paola Giuliano

NBER Working Paper No. 15747

February 2010, Revised June 2013

JEL No. J2,K2

\section{ABSTRACT}

Flexible labor markets require geographically mobile workers to be efficient. Otherwise firms can take advantage of the immobility of workers and extract rents at the expense of workers. In cultures with strong family ties, moving away from home is costly. Thus, to limit the rents of firms and avoid moving, individuals with strong family ties rationally choose regulated labor markets, even though regulation generates lower employment and income. Empirically, we do find that individuals who inherit stronger family ties are less mobile, have lower wages, are less often employed and support more stringent labor market regulations. We find a positive association between labor market rigidities at the beginning of the twenty first century and family values prevailing before World War II, and between family structures in the Middle Ages and current desire for labor market regulation. Both results suggest that labor market regulations have deep cultural roots.

\author{
Alberto F. Alesina \\ Department of Economics \\ Harvard University \\ Littauer Center 210 \\ Cambridge, MA 02138 \\ and IGIER \\ and also NBER \\ aalesina@harvard.edu \\ Yann Algan \\ Department of Economics \\ Sciences Po \\ 75007 Paris, France \\ 28 rue des Saints-Pères 75007 Paris \\ France \\ yann.algan@sciences-po.org
}

\author{
Pierre Cahuc \\ CREST, Ecole Polytechnique \\ 15 boulevard Gabriel Peri \\ 92245 Malakoff Cedex, France \\ cahuc@ensae.fr \\ Paola Giuliano \\ Anderson School of Management \\ UCLA \\ 110 Westwood Plaza \\ C517 Entrepreneurs Hall \\ Los Angeles, CA 90095-1481 \\ and IZA \\ and also NBER \\ paola.giuliano@anderson.ucla.edu
}




\title{
Family Values and the Regulation of Labor*
}

\author{
Alberto Alesina \\ Harvard University and IGIER Bocconi \\ Yann Algan \\ Pierre Cahuc \\ Paola Giuliano \\ Ecole Polytechnique, Crest \\ UCLA
}

June 10, 2013

\begin{abstract}
Flexible labor markets require geographically mobile workers to be efficient. Otherwise firms can take advantage of the immobility of workers and extract rents at the expense of workers. In cultures with strong family ties, moving away from home is costly. Thus, to limit the rents of firms and avoid moving, individuals with strong family ties rationally choose regulated labor markets, even though regulation generates lower employment and income. Empirically, we do find that individuals who inherit stronger family ties are less mobile, have lower wages, are less often employed and support more stringent labor market regulations. We find a positive association between labor market rigidities at the beginning of the twenty first century and family values prevailing before World War II, and between family structures in the Middle Ages and current desire for labor market regulation. Both results suggest that labor market regulations have deep cultural roots.
\end{abstract}

\section{Introduction}

Labor market institutions differ across countries and stringent labor market regulations persist despite being economically inefficient. ${ }^{1}$ In the present paper we endogeneize the choice of labor market institutions as a function of differences in cultural values, proposing

${ }^{*}$ We thank Murat Iyigun and seminar participants at Bocconi University, Brown University, Harvard University, the Kaler meeting at UCLA, IZA, IIES (Stockholm), the London School of Economics, Harvard University, New York University, Princeton University, the Terry College of Business, UC Berkeley Haas School of Business, University of Mannheim, University of Southern California, the AEA Meetings (Denver), the CEPR Conference on Culture and Institutions in Milan and the Politics, Information and the Macroeconomy conference in Barcelona for helpful comments.

${ }^{1}$ Most economists, although with varying emphasis, for example would argue that these regulations are at least in part responsible for the high European unemployment from the eighties onward. For a balanced view see Blanchard and Wolfers (2000). 
an interpretation based upon the complementarity between the strength of family ties and the stringency of labor market regulation. ${ }^{2}$ Flexible labor markets require that individuals move geographically in order to maximize their opportunities, find the best match with a firm and get the best paid job. This is efficient when mobility is painless. However, in certain cultures, staying close to the family is important and the mobility required by a free labor market is painful. With unregulated labor markets, local firms would have a market power (e.g. monopsonistic power) over immobile workers and would pay their reservation wage which could be below their productivity. Thus workers with strong family ties would favor labor regulation to counteract this power. This can lead to two different equilibria. One is laissez-faire, with high mobility and unregulated labor markets; this occurs when family ties are weak. When family ties are strong, there is another equilibrium with labor market rigidity comprising minimum wage and firing restrictions. Given the cultural value placed on family ties, labor market regulation is preferable to laissez-faire. Even though laissez-faire produces higher income per capita it rarefies family relations. If family ties are sufficiently strong this relaxation of family relationships can reduce individual utility so much that welfare can be higher with a regulated labor market. ${ }^{3}$

An innovative feature of our model is that individuals can choose the degree of family ties, or to be more realistic, they can educate their children in a certain way. This implies a two way effect between family ties and labor market regulation. An inherited culture of strong family ties leads to a preference for labor market rigidities, but the latter in turn makes it optimal to teach and adopt strong family ties. Thus economic incentives explain the evolution of cultural values and the other way around.

In our empirical analysis we study the interaction between family ties, labor market institutions and outcomes. We motivate our analysis by documenting a strong correlation

\footnotetext{
${ }^{2}$ The most common explanations for the persistence of rigidities in the labor market rely upon various versions of the insider-outsider model (Lindbeck and Snower (1989), Blanchard and Giavazzi (2003) and Saint-Paul (2000)), in which unionized "inside" workers want to preserve their rents and want to avoid competition from the outsiders. However, this interpretation does not explain why insiders are more powerful in some countries than in others. In addition, the logic of this model implies that the "outsiders" should oppose labor regulations, but in reality this is not the case. In fact those that could be considered outsiders favor extending the coverage to themselves as well rather than liberalizing the labor market.

${ }^{3}$ Our model does not have home production, but with strong family ties hours not spent at work can be devoted to work at home. Thus adding home production would reinforce the result of the model because lower work in the market would be less costly in strong family ties societies.
} 
at the country level between family ties (measured using a variety of subjective indicators on family values and objective measures of family arrangements) and labor market regulations. Our main empirical contribution relies however upon micro evidence. In particular, to mitigate problems of omitted variables and reverse causality, we rely on evidence from second generation immigrants in the US. ${ }^{4}$ We show that second generation immigrants coming from familistic societies are less mobile, face a wage and employment penalty and also ask for more government regulation of wages and job security. We also show that the strength of family values inherited from the countries of origin before World War II is positively correlated with the stringency of labor market regulation in the countries of origin at the beginning of the 21st century. Using regional variation in medieval family structures, we also document a correlation between desire for regulation today and the structure of the family dating back at least to the Middle Ages. Overall our evidence supports the idea that the relationship at the country level between actual regulation and family values goes through an individual desire for regulation influenced by transmission of cultural values.

The present paper contributes to the growing literature on the importance of cultural values in the determination of economic outcomes (see Guiso, Sapienza and Zingales2006- for a review). After establishing the relevance of cultural transmission (Bisin and Verdier, 2000 and 2001), ${ }^{5}$ this literature has moved forward and started looking at the interactions between culture and institutions. Tabellini (2008b) for example studies a model where individuals respond to incentives but are also influenced by norms of good conduct inherited from earlier generations. ${ }^{6}$ We contribute to this literature by looking at the interplay and coevolution of labor market institutions and a specific cultural trait of

\footnotetext{
${ }^{4}$ Cultural values are relatively slow to evolve, as a vast literature on the behavior of immigrants to other countries, mainly the US, shows. See for instance Alesina and Giuliano (2010), Algan and Cahuc (2005), Fernandez and Fogli (2006, 2009), Giuliano (2007), Guiso et al. (2006), Luttmer and Singhal (2009) amongst many others.

${ }^{5}$ See Bisin and Verdier $(2000,2001)$. Their model has been applied to the transmission of religious beliefs (Bisin and Verdier, 2000, and Bisin et al., 2004), of education (Patacchini and Zenou, 2006), of ethnic identity (Bisin et al. 2006), of moral values (Tabellini, 2008b) and the transmission of priors about the trustworthiness of others (Guiso et al. 2008).

${ }^{6}$ On the relationship between culture and institutions, Algan and Cahuc (2010) investigate the role of civic virtue on labor market institutions. On the link from regulation and institutions to culture, Alesina and Angeletos (2005), Alesina, Cozzi and Manotovan (2009), Alesina and Fuchs-Schündeln (2007), Aghion et al. (2011) and Aghion et al. (2010) show that regulation can shape beliefs like the demand for redistribution or beliefs in cooperation.
} 
a society, the strength of family ties. In addition, we look at the determinants of different values regarding the family by tracking their origin to the existence of different forms of family arrangements that go back to at least the Middle Ages. ${ }^{7}$

Our paper is also related to a vast area of research on labor market institutions and labor market performance. In particular, our paper contributes to the literature looking at the interaction between labor market institutions and geographical mobility (Hassler et al., 2005). ${ }^{8}$ More broadly, our paper provides a different, but however complementary analysis to the seminal insider outsider model on employment protection and minimum wage (Saint-Paul 2000, 2002). Finally, our paper contributes to the literature stressing the complementarity between investment in local social ties, including friends and family, and geographical immobility. ${ }^{9}$ Finally note that the most common explanations for the persistence of rigidities in the labor market rely upon various versions of the insideroutsider model (Lindbeck and Snower (1989), Blanchard and Giavazzi (2003) and SaintPaul (2000)), in which unionized "inside" workers want to preserve their rents and want to avoid competition from the outsiders. However, this interpretation does not explain why insiders are more powerful in some countries than in others. In addition, the logic of this model implies that the "outsiders" should oppose labor regulations, but in reality this is not the case. In fact those that could be considered outsiders favor extending the coverage to themselves as well rather than liberalizing the labor market.

The paper is organized as follows. The next section presents the model. Section 3 documents cross country correlations between family values and the regulation of labor.

\footnotetext{
${ }^{7}$ Alesina and Giuliano (2010) and Algan and Cahuc (2007) show that differences in family culture could help explain heterogeneity in labor market participation (especially for women and young adult).

${ }^{8}$ Hassler et al. (2005) find a negative relationship between unemployment insurance and geographical mobility. In their theoretical interpretation, differences in the propensity to move are given and are not a function of a particular cultural trait. Also the paper does not provide an empirical test of their theory.

${ }^{9}$ Glaeser, Laibson and Sacerdote (2002) argue that individuals who perceive themselves as being strongly attached to a village, a township or a region, may invest in local social capital, because the returns from these local ties are high while, on the other hand, strong local social capital raises the cost of mobility and in turn reduces incentives to move. Spilimbergo and Ubeda (2004a) show that interactions between social ties and moving decisions can explain the different behaviors of workers in different groups, regions, or countries in an endogenous way by showing the existence of multiple equilibria. Glaeser and Redlick (2008) show that it is possible that an area can get caught in a bad equilibrium where the prospect of out-migration reduces social capital investment and a lack of social capital investment makes out-migration more appealing. David, Janiak and Wasmer (2009) build a model that can include two different equilibria: strong local social capital and low mobility vs. low social capital and high propensity to move.
} 
Section 4 looks at economic outcomes and attitudes of second generation immigrants. Section 5 further documents the issue of persistence and Section 6 concludes.

\section{The model}

\subsection{The setup}

There are two goods: labor and a numeraire good produced with labor and a continuum of individuals of mass one. Individuals are uniformly located on the $[0,1]$ line. They are identical, risk neutral and have no preference for leisure: their utility is equal to the sum of their consumption and a term that represents the valuation of family ties to be defined below. Family ties are public information. The timing is as follows:

1. At birth, every individual is located on the $[0,1]$ line, on a point where her parents live. Then, individuals choose family values which can be either with strong family ties or with low family ties. The choice of family values is irreversible. In reality family values are "chosen" by parents and transmitted to children. However for the sake of simplicity we collapse the model to a static case without intergenerational transmission of values. Below we also make some progress toward extending our model in a dynamic direction.

The share of individuals with strong family ties is $\sigma \in[0,1]$ to be determined endogenously. Strong family ties yield an utility $\Delta(\sigma)>0$, if an individual lives in the same location as her parents, and a disutility $-\Delta(\sigma)$ if he/she lives elsewhere. An individual with weak family ties is indifferent between living in his location of birth or elsewhere, thus $\Delta=0$ for any $\sigma$. We assume $\Delta^{\prime}(\sigma) \geq 0$. This assumption is plausible for a variety of reasons. First, social norms are generally more influential when they are more widespread. Living in a community where most people have strong family ties create a strong social norm to which one feels an incentive to conform. In addition, when the share of the population with strong family ties is larger, individuals with weak family ties and those who do not live in the neighborhood of their parents have less opportunities to have social interactions. This may imply that the relative value of strong family ties compared to weak family ties (which is normalized to zero) increases with the share of individuals with strong family ties. It is worth stressing that the assumption that the valuation of family ties depends on the share of individuals with strong family ties is innocuous for our 
main results. In particular our results hold even when $\Delta^{\prime}(\sigma)=0$, as it will become clear below. But we start from the more general model in this section. Also note the difference between the mobility costs associated with family ties and those associated with simple transaction costs of moving. The latter are not a choice variable and depend on the technology of transportation. Besides they are in general not decreasing with the number of people who move; and, in fact, they can even increase in case of congestion.

2. With majority rule individuals vote on labor market regulation. By assumption there are two possible types of labor market policies: either labor market flexibility (i.e. laissez-faire on the labor market), or regulation of wages and employment based upon two instruments, a minimum wage and job protection.

3. Firms offer labor contracts. When a worker is hired in his/her initial location, his/her productivity $y$ is drawn from the uniform distribution on the interval [0,1]. Every worker can find a job with productivity 1 in a place different from his/her initial location. Job protection constrains firms to keep all employees whose productivity is above a threshold value denoted by $R \in[0,1]$. Job protection entails deadweight losses $c \in[0,1)$, that is the production of a worker who draws the productivity $y$ is equal to $y-c$, instead of $y .{ }^{10}$ In each location, there is a single firm that offers labor contracts. In this setup, workers are paid at their reservation wage, which can be lower than their productivity if there are mobility costs. ${ }^{11}$ When there is a minimum wage, workers can be either employed and paid the minimum wage, denoted by $w$, or unemployed. They are unemployed if their productivity $y$ is below the reservation productivity $R$ of the firm.

The nature of these assumptions should be clear. A worker with weak family ties would always manage to find a job with productivity $y=1$ since he bears no costs of mobility. A worker with strong family ties has a moving cost of $2 \Delta(\sigma)$. Without labor market regulation, workers with strong family ties face the monopsony power of firms. Labor market regulation protects these workers against those firms.

\footnotetext{
${ }^{10}$ The latter can take a variety of forms, including the distortionary cost of taxation needed to provide unemployment subsides for those not employed in distorted labor market. We do not explicitly model this channel.

${ }^{11}$ The important assumption here is that mobility costs decrease wages. This property could be obtained in a search and matching model à la Mortensen and Pissarides, see e.g. Pissarides (2000).
} 


\subsection{Solution}

The model is solved by backward induction.

i) In stage 3, the labor market is either regulated or flexible, and the share of individuals with strong family ties is given.

\section{Flexible labor market}

If the labor market is flexible, individuals with weak family ties obtain a wage equal to 1 by moving at no cost. Their utility level is

$$
U_{F}^{W}=1
$$

Individuals with strong family ties get a wage equal to 1 if they decide to leave their initial location, but the move costs them $2 \Delta(\sigma)$. Therefore, their reservation wage, which is necessarily non negative, is equal to $\max [0,1-2 \Delta(\sigma)]$. Thus individuals with strong family ties get a wage equal to 0 and stay in their initial location if $\Delta(\sigma)$ is larger than $1 / 2$. In that case, their utility is equal to the valuation of family ties, $\Delta(\sigma)$. If $\Delta(\sigma)$ is smaller than $1 / 2$, two possibilities can arise.

1. If their productivity in their initial location is larger than their reservation wage, equal to $1-2 \Delta(\sigma)$, they keep their job in their initial location. In that case, they are paid their reservation wage and they are immobile. Their utility is equal to their reservation wage plus the valuation of family ties, i.e. $1-2 \Delta(\sigma)+\Delta(\sigma)=1-\Delta(\sigma)$

2. If their productivity in their initial location is smaller than their reservation wage, individuals with strong family ties are not hired. Since $\Delta(\sigma)<1 / 2$, individuals with strong family ties prefer to move and get a utility equal to $1-\Delta(\sigma)$. In conclusion, when the labor market is flexible, the utility of individuals with strong family ties is

$$
U_{F}^{S}=\max [\Delta(\sigma), 1-\Delta(\sigma)]
$$

\section{Rigid labor market}

If the labor market is regulated, the government sets a minimum wage and job protection. For every worker, the probability to get a job offer in the firm located in his/her initial birth place is equal to the probability to draw a productivity $y$ larger than the reservation productivity $R$. With the uniform distribution, this probability is equal to 
$1-R$. If the productivity is higher than $R$, individuals can get the minimum wage $w$ in their birth place, or leave the firm and obtain a wage equal to $1-c$ elsewhere, where $c$ denotes deadweight losses associated with job protection. ${ }^{12} \quad R$ and $w$ are determined endogenously below in equilibrium. When the productivity is lower than $R$, individuals get either zero income if they do not move, or a wage equal to $1-c$ if they move. Individuals with weak family ties get the expected utility

$$
U_{R}^{W}=(1-R) \max (1-c, w)+R(1-c) .
$$

The expected utility of individuals with strong family ties is

$$
U_{R}^{S}=(1-R) \max [w+\Delta(\sigma), 1-c-\Delta(\sigma)]+R \max [\Delta(\sigma), 1-c-\Delta(\sigma)]
$$

ii) In stage 2, people vote on the labor market policy: either regulation or flexibility. The share of individuals with strong family ties, chosen in stage one, is given. There are only two types of voters, so that the median voter can have either strong family ties or weak family ties. We assume that the owners of the firms do not vote. If they did they would always prefer labor market flexibility regardless of the level of family ties therefore they have a dominant strategy to vote for flexibility. Their share of votes should be simply added to those who vote for laissez-faire. ${ }^{13}$

- Individuals with weak family ties obtain $U_{F}^{W}=1$ under labor market flexibility, and $U_{R}^{W}<1$ under labor market regulation. ${ }^{14}$ Therefore, individuals with weak family ties always prefer labor market flexibility. This implies that the outcome of the vote is labor market flexibility if the share of people with strong family ties, $\sigma$, is smaller than $1 / 2$.

- Now, consider the case where $\sigma>1 / 2$, so that the median voter has strong family ties. For the sake of simplicity, assume that all individuals with strong family ties are immobile if the majority of the population has strong family ties under flexible labor market. According to equation (2), this requires that:

\footnotetext{
${ }^{12}$ Assuming that firms can make counter offers so that only weak family ties workers with productivity $y<1-c$ and strong family ties workers with productivity $y<1-c-2 \Delta(\sigma)$ move, would not change the qualitative results of the model.

13 In case workers own stocks of firms then some of them would face a trade off between their interest as stock holders and those as workers. We do not explore this extension here. In most countries the percentage of individuals who hold stocks is small.

${ }^{14}$ When the labor market is rigid, the expected utility of workers with weak family ties is smaller than 1 because $R \in[0,1]$ and the wage cannot be larger than $1-c$. Otherwise firms would get negative profits.
} 
Assumption 1: $\Delta(1 / 2)>\frac{1}{2}$.

This assumption implies that when the labor market is regulated, workers with strong family ties do not move. This case is easier to illustrate and we do so in the text. The general case without that assumption is in the appendix.

Assumption 1 implies that the expected utility of individuals with strong family ties when the labor market is flexible and when $\sigma>1 / 2$ is:

$$
U_{F}^{S}=\Delta(\sigma)
$$

On the other hand, the expected utility in the regulated scenario is given by:

$$
U_{R}^{S}=(1-R) w+\Delta(\sigma)
$$

Comparison of equations (5) and (6) shows that those with strong family ties prefer a regulated labor market rather than a flexible one.

The optimal labor market regulation is the set of values of the minimum wage $w$ and of the reservation productivity $R$ that maximizes the expected utility of workers with strong family ties, as defined by equation (6) and subject to the zero profit condition

$$
\int_{R}^{1}(y-c-w) \mathrm{d} y=0 .
$$

It is easily checked that the solution is

$$
R=c \text { and } w=\frac{1-c}{2}
$$

The solution shows that labor market regulation comprises a binding minimum wage and job protection which forces firms to keep employees whose productivity is lower than their labor cost. In this equilibrium, every worker with strong family ties can be either employed (with probability $1-c$ ) or unemployed (with probability $c$ ) and remains in his/her initial location. Profits are equal to zero. The wage is smaller than 1 and also smaller than the wage under flexible labor markets. Employment is equal to $1-\sigma c$, since all individuals with weak family ties are employed (the share of individuals with strong family ties is equal to $\sigma$, and a share $c$ of individuals with strong family ties are unemployed). Thus employment is lower when the labor market is regulated, since employment is equal to 1 
when the labor market is flexible. Workers with strong family ties get the expected utility (see equations (6) and (8)):

$$
U_{R}^{S}=\frac{(1-c)^{2}}{2}+\Delta(\sigma)
$$

which is larger than $\Delta(\sigma)$, the utility they would get if the labor market were flexible.

In conclusion, the outcome of the vote is for market regulation if $\sigma>1 / 2$; and for labor market flexibility otherwise.

iii) In stage 1, individuals choose their family values with perfect foresights. If they anticipate that the share of individuals with strong family ties is smaller than $1 / 2$, they know that labor market flexibility will prevail. Otherwise, the outcome of the vote will be labor market regulation. Therefore, the payoff of individuals with strong family ties is

$$
\begin{cases}\max [\Delta(\sigma), 1-\Delta(\sigma)] & \text { if } \sigma \leq 1 / 2 \\ \Delta(\sigma)+\frac{(1-c)^{2}}{2} & \text { if } \sigma>1 / 2\end{cases}
$$

and the payoff of individuals with weak family ties is ${ }^{15}$

$$
\begin{cases}1 & \text { if } \sigma \leq 1 / 2 \\ 1-c & \text { if } \sigma>1 / 2\end{cases}
$$

Thus, the utility gains of choosing strong family ties rather than weak family ties are

$$
\Gamma(\sigma)= \begin{cases}\max [\Delta(\sigma), 1-\Delta(\sigma)]-1 & \text { if } \sigma \leq 1 / 2 \\ \Delta(\sigma)-\frac{1-c^{2}}{2} & \text { if } \sigma>1 / 2\end{cases}
$$

In a Nash equilibrium, every individual takes $\sigma$ as given and chooses strong family ties if the gains of doing so are positive, and weak family ties otherwise. At this stage, it turns out that there exists an equilibrium with weak family ties only if we make the relatively innocuous: ${ }^{16}$

Assumption 2: when the share of population with strong family ties goes to 0 , the utility gains induced by strong family ties are smaller than the maximum wage gains obtained by changing of location: $\Delta(0)<1$.

\footnotetext{
${ }^{15}$ When the labor market is rigid, the minimum wage, $w=(1-c) / 2$, obtained by immobile workers, is smaller than $1-c$, the wage of mobile workers. This implies that individuals with weak family ties are always mobile.

${ }^{16}$ If this assumption were not satisfied then the value of family ties in a society where nobody else values them is larger that the maximum salary that one can obtain in the market.
} 


\subsection{Equilibria}

Under assumptions 1 and 2, Figure 1 shows the function $\Gamma(\sigma)$ which implies two stable Nash equilibria. There is an equilibrium (point A on Figure 1) where everybody chooses weak family ties and then vote for labor market flexibility. In that case, the labor market is competitive: everyone is paid his marginal productivity. Labor mobility is high since everyone changes his location in this equilibrium. On the other hand, there is another equilibrium (point B on Figure 1) where everyone chooses strong family ties and then vote for stringent labor market regulation. The labor market is monopsonistic because workers are immobile. This is the reason why people vote for stringent labor market regulation.

Production, employment and wages are lower with rigid labor markets than with flexible labor markets. However, it is important to remark that the equilibrium with flexible labor markets does not necessarily Pareto-dominate the equilibrium with rigid labor markets. Actually, the equilibrium with rigid labor markets and strong family ties dominates if $\Delta(1)>1-\frac{(1-c)^{2}}{2}$, since the expected utility is $\Delta(1)+\frac{(1-c)^{2}}{2}$ in the equilibrium with strong family ties and 1 in the equilibrium with weak family ties. Otherwise, the equilibrium with weak family ties yields higher welfare. Accordingly, the economy can be coordinated on an equilibrium with too rigid labor markets, when $\Delta(1)<1-\frac{(1-c)^{2}}{2}$, but also on an equilibrium with too flexible labor markets, when $\Delta(1)>1-\frac{(1-c)^{2}}{2}$. As shown in Figure 2, it turns out that labor market regulation is the preferred equilibrium if the valuation of strong family ties when everyone has strong family ties, $\Delta(1)$, is high relative to $c$, the cost of labor market regulation.

A slightly different way of rephrasing this result is that in countries or historical periods when family ties can bring about great gains then the benefits of family ties may compensate for the loss of efficiency caused by labor market regulations.

\subsection{The dynamics of family values}

Following the seminal papers by Bisin and Verdier (2000, 2001), we assume that paternalistic parents wish to transmit their own values to their children. Suppose that each individual lives for one period, has one child, and has payoffs as before. Her child inherits her family values with probability $p>1 / 2$ and is free to choose her family values with probability $1-p$. As it will be clear below, $p>1 / 2$ ensures that the transmission of family 
ties influences the dynamics of labor market regulation. When $p \leq 1 / 2$, the stickiness in the transmission of family ties is not sufficient to influence the choice of labor market regulation.

The sequence of events outlined above is now repeated in each period with an infinite horizon, with the only change being that only a fraction $1-p$ of the population chooses family values; a fraction $p \sigma_{t-1}$ is constrained to have strong family ties and a fraction $p\left(1-\sigma_{t-1}\right)$ to have weak family ties. In other words we add some stickiness to the transmission of family ties. Not everyone can freely choose a set of family ties every generation.

- If $\sigma_{0}>1 / 2 p$, the share of individuals with strong family ties is necessarily larger than $1 / 2$ in period 1 . Then, the median voter chooses to regulate the labor market and every individual is better off with strong family ties. Since there are at least $p\left(1-\sigma_{0}\right)$ individuals with weak family ties in period 1 , the share of individuals with strong family ties in period 1 is

$$
\sigma_{1}=1-p\left(1-\sigma_{0}\right)>1 / 2
$$

Then, in periods $t \geq 1$, the labor market is regulated and the share of individuals with strong family ties

$$
\sigma_{t}=1-p^{t}\left(1-\sigma_{0}\right)
$$

converges to one when $t$ goes to infinity.

- If $\sigma_{0}<1-(1 / 2 p)$, the same type of reasoning shows that the economy has a flexible labor market in period $t>0$ and that

$$
\sigma_{t}=\sigma_{0} p^{t}
$$

converges to zero when $t$ goes to infinity.

- If $\sigma_{0} \in[1 / 2 p, 1-(1 / 2 p)]$, there are two possible equilibria in periods $t>0$ as far as $\sigma_{t-1}$ remains in the interval $[1 / 2 p, 1-(1 / 2 p)]$. If $\sigma_{t-1}$ does not belong to this interval, the dynamics of $\sigma$ after date $t$ is described by one of the two cases described above. 
This simple analysis shows how societies starting with a large share of individuals with strong family ties have strong labor market regulations, whereas societies starting with weak family ties have flexible labor markets. This analysis shows a two way interaction between culture and institutions.

\section{Family ties and labor market regulation: cross coun- try evidence}

Our model predicts a two way relationship between family values and labor market regulation. Testing a multiple equilibrium model is very hard, as one would need to have exogenous variation in labor market institutions and family values. In our empirical part we try however to establish few important facts. First, we show that it exists a strong correlation between family values and labor market regulation, that is not driven by other country characteristics. We motivate our analysis by documenting a strong correlation between the strength of family relationships and labor market regulations (and also desire for regulations) across countries. We then analyze economic outcomes and attitudes toward regulation of children of immigrants to further limit the possibility that our results are driven by omitted variables. In the last section we go one step further and try to isolate one part of the feedback effect: the one going from cultural values to labor market regulation. We do so by documenting a strong correlation between the structure of the family in the Middle Ages and current desire for regulation today. In addition, we show that values inherited by children of immigrant prior to 1940 (therefore before the establishment of actual labor market regulations) are relevant in shaping institutions today. Although we are able to establish a strong link between cultural values and labor market regulations, our last piece of evidence is an indication that cultural values are more primitive than labor market institutions or definitely more slow moving.

\subsection{Data}

\subsubsection{Family ties}

We measure the strength of family ties by using a series of objective and subjective measures of family ties. We use two main data sources: the World Values Survey (WVS) 
and the Survey of Health, Ageing and Retirement in Europe (SHARE).

The WVS is an international social survey of four waves 1981-84, 1990-93, 1995 and 1999-2003, denoted henceforth 1980, 1990, 1995 and 2000. This survey provides, among other things, a wide range of subjective indicators on the relationship between parents and children and, as an objective measure of family attachment, whether the individual lives with his/her parents. We measure family strength using the following five measures:

i) living with parents: the question is an objective indicator of family strength and measures whether a young adult is living at home with his/her parents. Reher (1998) in studying differences between weak and strong family ties in Europe indeed claims that "the strength and weakness refers to cultural patterns of family loyalties, allegiances, and authorities which are reflected in demographic patterns of coresidence with adult children and older family members".

ii) respect parents: the question probes whether the respondent agrees with one of the two statements (taking the values of 1 and 2 respectively): 1) regardless of what the qualities and faults of one's parents are, one must always love and respect them; 2) one does not have the duty to respect and love parents who have not earned it.

iii) make parents proud: the question asks the respondents to agree or disagree (on a scale from 1, agree strongly, to 4, strongly disagree) with the following statement: one of the main goals in life has been to make my parents proud.

iv) parents' responsibility: the question investigates whether the respondent agrees with one of the two statements (taking the value of 1 and 2 respectively): 1) It is the parents' duty to do their best for their children even at the expense of their own well being, 2) Parents have a life on their own.

$v$ ) obey parents: the question asks whether obedience is an important quality for children and can take the value of 1 if it is indeed important and 0 if it is not.

vi) family important: this question assesses how important the family is in one person's life and can take values from 1 to 4 (with 1 being very important and 4 not important at all).

We recode all the questions so that a higher number implies a stronger attachment to the family and collapse the data at the country level to be able to correlate them to measures of labor market regulations across countries. 
The SHARE database is a cross-national database that provides micro data on health, socio-economic status and the social and family network of individuals, aged 50 or over, for 14 European countries. ${ }^{17}$ For our purposes, the SHARE survey has the advantage of collecting detailed information on child-parent geographic proximity. From this survey we constructed three different indicators of family attachment at the country level: ${ }^{18}$ the first indicator measures the fraction of adult children (older than 24), who live $5 \mathrm{Km}$ or closer to their family. The second indicator measures the average age at which the young adult left home, and the third indicator measures the frequency of contacts parents have with their children (this variable, increasing with frequency, is coded on a scale from 1 (never) to 7 (daily) $)^{19}$.

\subsubsection{Labor market regulation and desire for labor market regulation}

We focus on the labor market institutions analyzed in the model: firing costs and the stringency of the minimum wage regulation. Firing costs are measured using the index of the World Bank for the year 2004 (see Botero et al., 2004). This index measures these costs in terms of weeks of salary. It is based on three components: i) the notice period for redundancy dismissal after 20 years of continuous employment, ii) the severance pay for redundancy dismissal after 20 years of employment and iii) the legally mandated penalty for redundancy dismissal. We mainly focus on this indicator because it covers much more countries than the OECD employment protection index, and it displays more heterogeneity than the World Bank indicator of the difficulty of firing. The index can take values from 0 to 200. For robustness checks, we also consider the OECD employment protection index. We take the most recent indicator in 2008, covering 33 countries for which we have observations on family ties. The recent trends in labor market regulations are that countries with more rigid labor markets have introduced some flexibility for particular population groups. The question of why some countries impose a more rigid

\footnotetext{
${ }^{17}$ This paper uses the second release of the 2006 wave, which includes the following countries: Austria, Belgium, Czech Republic, Denmark, France, Germany, Greece, Ireland, Italy, Netherlands, Poland, Spain, Sweden, Switzerland.

${ }^{18}$ We constructed the indicator using the information on the first child; the survey also reports information for the other children. The results remain valid when we look at the second or third child or an average of all the children.

${ }^{19}$ The variable can take the following values: never (1), less than once a month (2), about once a month (3), about every two weeks (4), about once a week (5), several times a week (6), daily (7).
} 
regulation for some groups than on others is beyond the scope of this article. But we check that the legislation on temporary contracts is still more stringent in countries with stronger family ties than in countries with weak family ties. The indices on regular contracts and temporary contracts ranges from 0 for the least stringent regulation to 6 for the most restrictive legislation. The index on temporary contracts covers both fixed term contracts and all other kinds of short term contracts.

The stringency of the minimum wage regulation is measured through a composite index constructed by the ILO. ${ }^{20}$ The index combines information $i$ ) on the level of the minimum wage and $i i$ ) on the existence of legal minimum wages and the extent of potential derogation. The index refers to the year 2006. The first component of the index, the level of the wage floor, is measured as the monthly minimum wage expressed in US dollars. To make this measure comparable across countries, we calculate the share of the monthly minimum wage as a function of per capita income in 2006. Income per capita is taken from the World Bank. The second component of the index measures the stringency of the minimum wage legislation, that is the extent to which the state directly regulates by law the labor market instead of letting social partners negotiate. This component can take the following values:

- 1 if there is a legal statutory minimum wage and if the minimum wage is set at the national level without any derogation.

- 0.5 if there is a legal statutory minimum wage but with derogations by age, qualification, region, sector or occupation; or if the wage floor is set by collective bargaining but extended to all workers.

- $\mathbf{0}$ if the wage is set by collective bargaining and only applies to the unionized workers. The overall index is the product of these two components.

We measure the desire for labor market regulation aggregating at the country level the following two subjective measures. First, for the demand for job security we use the following question in the four waves of the WVS "Here are some more aspects of a job that people say are important. Please look at them and tell me which ones you personally

\footnotetext{
${ }^{20}$ This index is described more precisely in Aghion, Algan and Cahuc (2011).
} 
think are important in a job?: Good Job Security". The answers take on the value 1 if job security is mentioned and zero otherwise. Second, for wage regulation we use the International Social Survey Program. The ISSP is a compilation of surveys, covering all OECD and Eastern European countries, devoted each year to different specific topics such as religion, social networks or the role of government. A specific ISSP survey on "The role of government" was carried out in 1996, providing a specific question on the regulation of wages: "Here is a list of potential government actions for the economy: Control wages by law?". The answers can take on values from 1, strongly agree, to 4 , strongly disagree. To ease the interpretation we recode the question as a dummy taking the value of 1 if the respondent (strongly) agrees and 0 if he/she (strongly) disagrees. The results remain unchanged with the original coding.

\subsection{Cross country correlations}

Figures 3 shows the positive cross-country correlation between the two measures of labor market regulation (firing costs and the minimum wage) and the objective indicator of family ties, measured by the fraction of young adults living in the parental home. ${ }^{21}$ Countries with strong family ties tend to have higher firing costs and also more stringent regulation of the minimum wage. Figure 3 bis shows the relationship between family ties and the alternative OECD index of employment protection, distinguishing between regular and temporary contracts. We find the same correlation pattern. The cross-country correlation between the legislations on temporary and on regular contracts is modest, reaching 0.388. But we find that OECD countries with strong family ties, in particular in Southern European countries, have also more stringent legislation on temporary contracts.

Figure 4 shows the relationship between desire for regulation (demand for wage and job security) and the strength of family ties. The correlation between those labor market institutions and the demand for those types of regulation is substantial, suggesting to probe into the determinants of the demand for regulation.

In the Appendix (Table B2) we report the correlations with additional controls. We include legal origin, which is the traditional alternative theory to explain regulation and

\footnotetext{
${ }^{21}$ We do the cross-country analysis using the objective measures of family ties. The results with the subjective measures are very similar and are available from the authors. The correlations between the different measures of family ties are very strong and are reported in Table 1.
} 
its economic consequences (see Botero et al., 2004; or Laporta et al., 2008). We also include the (ln)-country average population over the period 1980-2000 (taken from the World Bank). As stressed by Mulligan and Shleifer (1995), the population density might be crucial to explain the supply of regulation. The relationship between labor market regulation or desire for regulation and family ties remains positive and statistically significant at the 1 or 5 percent level. The only relationship that is no longer statistically significant is with the demand for wage regulation, but this is most likely due to the low number of observations. The economic impact of family ties is sizeable. A one standard deviation increase in the strength of family ties (0.104) is associated with a 10.4 percent increase in firing costs (equal to 22 percent of the sample mean of the firing cost variable). A one standard deviation increase in the strength of family ties also explain 17 percent of the sample mean of the minimum wage variable and 9 percent of the sample mean of the demand for job security ${ }^{22}$.

In Figures 5 and 6, we show the correlations between labor market regulation (and desire for labor market regulation) and the three additional objective measures of family attachment constructed from the SHARE survey. The picture found with these additional measures is very consistent with our previous findings: countries with strong family ties demand and choose more regulated labor market institutions.

\section{Evidence from immigrants in the United States}

Cross-country correlations are only illustrative because omitted variables and reverse causality may influence the relationship we are interested in. The omitted variable problem is obvious: many other variables besides family ties may explain differences in labor market institutions across countries. In order to avoid this problem one could look at within country evidence comparing preferences for labor market regulation at the individual level (i.e. running individual level regressions with country fixed effects). However even this empirical strategy suffers from a problem of reverse causality. For instance

\footnotetext{
${ }^{22}$ Table B2 bis shows the results with the OECD employment protection indexes. We report the results for temporary and regular contracts and also for the global index (an average of the two types of legislations weighted by the share of workers covered by each contract.) We still find a statistically significant correlation with family ties, at the 10 percent level though, but the number of observations is reduced by half when the sample includes OECD countries only.
} 
somebody with low productivity and unwilling to move because of "laziness" may justify to himself/herself (and/or to the interviewer) his/her lack of effort with an attachment to his/her family and a desire to stay home.

We address both concerns by looking at immigrants in the US. We associate to each immigrant the family values of his/her country of origin, as measured by objective and subjective measures of family ties in the World Value Survey. Family values attributed to any immigrant are those of the country of origin and not those that he/she expresses (and that therefore could be caused by his/her special circumstances.) We look at second generation immigrants (individuals who are born and raised in the US), because problems of disruption and selection due to immigration are more limited compared to the first generation (those who actually moved.) We provide evidence on both immigrants' outcomes (unemployment, mobility and wages) and their desire for labor market regulation. We show that immigrants coming from more familistic societies are less mobile, face a wage and employment penalty and also ask for more government regulation of wages and job security. ${ }^{23}$ The results hold not only when we use the objective measure of family ties but also the five different subjective measures calculated from the World Values Survey.

The benefit of this exercise is that we are holding constant the external environment, while examining individuals from diverse cultural backgrounds. One shortcoming is that the children of immigrants are not a random sample of the full population in the home country. Therefore, the results should be understood with this in mind: they are an average effect of the sample we consider. It is worth notice, however, that in this specific case the results should be biased against us: individuals coming from weak family ties are indifferent between staying in the country of origin and leaving, but for people coming from strong family ties countries those who left should be less attached to the family. As a result, we should see less variation among immigrants and as such our estimates most likely constitute a lower bound of the effect of family values on labor market outcomes. Another shortcoming of the analysis is that if immigrants and their children tend to live in locations with many co-ethnics, then it is possible that informal institutions may

\footnotetext{
${ }^{23}$ The use of immigrants (first or second generation) to study the importance of culture on economic behavior is becoming relatively standard in the analysis of culture. See Alesina and Giuliano (2010), Algan and Cahuc (2005, 2009), Antecol (2000), Carroll, Rhee and Rhee (1994), Fernandez and Fogli (2006,2009), Giuliano (2007) and Guiso, Sapienza and Zingales (2006) among others.
} 
be recreated in these areas, explaining some of the persistence. The results should be understood with this possibility in mind.

\subsection{Data and empirical specification}

We use two main datasets: the March Supplement of the Current Population Survey to study immigrants' economic outcomes and the General Social Survey (GSS) to study immigrants' attitudes towards labor market regulation.

\subsubsection{March Supplement of the Current Population Survey: 1994-2012}

The March Supplement of the Current Population Survey (CPS) is the only recent available dataset in which individuals were asked (starting from 1994) about their parents' country of origin. ${ }^{24}$ We define second generation immigrants by looking at the country of origin of fathers' respondent in order to maximize the number of observations. ${ }^{25} \mathrm{We}$ pool nineteen years of data, from 1994 to 2012, to have a higher number of observations. We use the CPS to study the following outcomes predicted by the model: geographical mobility, unemployment and wages. In the CPS we do have data on almost all countries covered in the World Values Survey. ${ }^{26}$ Descriptive statistics are provided in Table B1.

\subsubsection{General Social Survey: 1972-2010}

The General Social Survey (GSS) covers the period 1972-2010 and provides information on the place of birth and the country of origin of the respondent's forbearers since 1977. The GSS variable for the country of origin reads as follows: "From what countries or part of the world did your ancestors come?". The individual can report up to three countries of origin by order of preference. Two respondents out of three report only one country of origin. We select the GSS ethnic variable that captures the country of origin

\footnotetext{
${ }^{24}$ The Census reports the information about the father's country of origin until 1970.

${ }^{25}$ The CPS also reports the country of origin of the mother, but the sample size would be smaller due to a much higher number of missing observations.

${ }^{26}$ The CPS has data on second generation individuals from the following countries of origin: Puerto Rico, Canada, Mexico, El Salvador, Dominican Republic, Argentina, Brazil, Chile, Colombia, Peru, Uruguay, Venezuela, Finland, Norway, Sweden, England, Ireland, Northn Ireland, Belgium, France, Netherlands, Switzerland, Greece, Italy, Portugal, Spain, Austria, Slovakia, Czech Republic, Germany, Hungary, Poland, Yugoslavia, Latvia, Lithuania, Tussia, Ukraine, China, Taiwan, Japan, South Korea, Indonesia, Philippines, Singapore, Vietnam, India, Bangladesh, Pakistan, Iran, Jordan, Turkey, Egypt, Morocco, Nigeria, South Africa, Australia and New Zealand.
} 
to which the respondent feels the closest to make the comparison between countries of origin interpretable. To maximize the number of observations we combine all generations, therefore we define an immigrant as a person with at least one ancestor (parent or grand parents) born abroad. The descriptive statistics are reported in Table B1 in the Appendix.

The GSS provides specific questions related to attitudes towards job security and regulation. Preferences for job security are measured by the question: "Would you please look at this card and tell me which one thing on this list you would most prefer in a job? No danger of being fired". The answer is ranked from 1, for the most important characteristic, to 5 for the last important. Attitudes toward regulation of jobs and wages are given by the following two questions: "Here are some things the government might do for the economy: Supporting declining industries to protect jobs". "Here are some things the government might do for the economy: Regulate wages". The answers range from 1 for strongly agree, 2 for agree, 3 for neither, 4 for disagree to 5 for strongly disagree. We recode all the questions so that a higher number is associated with a higher desire for regulation.

\subsubsection{Empirical Specification}

For both attitudes and labor market outcomes, we run the following OLS or probit (depending on the nature of the left hand side variable) regressions:

$$
Y_{i c}=\alpha_{0}+\alpha_{1} \text { family_ties }{ }_{c}+\alpha_{2} X_{i}+\delta_{s}+\varepsilon_{i c}
$$

where $Y_{i c}$ is our variable of interest for an immigrant $i$ whose forbearer was born in country c. $X_{i}$ are individual controls, which vary according to the nature of the left hand side variable, and family_ties $s_{c}$ are different measures of family ties calculated from the WVS in the country of origin. We also control for a full set of US state dummies ${ }^{27}$. All standard errors are clustered at the country of origin level.

\footnotetext{
${ }^{27}$ When we use the GSS we include region fixed effects, since the information about the state of residence is not available in the publicly available version.
} 


\subsection{Results}

\subsubsection{Evidence on labor market outcomes}

We start by analyzing the impact of country of origin family ties on labor market outcomes of second generation immigrants. Tables 2 to 4 report the evidence obtained with the CPS for the following labor market outcomes: mobility, unemployment and log real hourly wages. Mobility is defined as a dummy equal to 1 if the individual moved from/in a different state, or abroad in the last five years. Unemployed is a dummy equal to 1 if the person is unemployed. Log hourly wage is defined as total wage income divided by the number of hours worked in a year, and corrected for inflation ${ }^{28}$.

We regress each outcome on the different measures of family ties. The mobility regression (Table 2) controls for education, marital and employment status, real family income, number of children in the household, in addition to gender, race and a quadratic term for age. The standard errors are clustered at the country of origin level. Our specification also includes state dummies to take into account local labor market characteristics of the area where immigrants live that could drive the results. Although we do not report them explicitly in here, we find that the estimated coefficients for the control variables are generally as expected..$^{29}$ In particular unemployed individuals are more likely to move (presumably searching for jobs). Less educated people are less mobile and higher income tends to discourage mobility, controlling for education. Married people tend to move less, similarly to women (although the gender effect is not significant). The results are significant and with the expected sign for each measure of family values: individuals coming from countries with stronger family ties, display lower mobility.

Table 3 reports the results for the probability of being unemployed. We find that the probability of being unemployed is indeed substantially higher ${ }^{30}$ for immigrants coming from countries with stronger family ties. ${ }^{31}$ Thus, looking at Tables 2 and 3, the picture

\footnotetext{
${ }^{28}$ The CPS has information on both the number of weeks worked in a year and the number of hours usually worked in a week. When correcting for inflation we use as base year the CPI 1994.

${ }^{29}$ The estimates for the controls are available upon request.

${ }^{30} \mathrm{We}$ do not find a significant effect on the variable indicating the fraction of people living at home in the country of origin. Note that this variable is however significant when we look at the probability of being unemployed for second generation immigrants in the Census 1940, 1960 and 1970. The results are reported in Tables B20-B22 of Appendix B.

${ }^{31}$ This result is also in line with Bentolila and Ichino (2008), who find that the losses associated with unemployment are much lower in Mediterranean societies with strong family ties, as the family provides
} 
seems to be consistent with the model: with stronger family ties people are less willing to move to find jobs.

Table 4 reports a standard Mincer wage regression where log hourly wages are regressed on education and a quadratic in potential experience (defined as age minus number of years of education minus six). We also control for marital status and gender. Higher experience increases wages, as expected, together with education. Single people and women tend to have lower wages. All the different measures of family values have a significant effect on wages: second generation immigrants coming from familistic countries have lower wages as predicted by our model.

In terms of magnitude of the results, we can easily compute the impact of a one standard deviation increase in different measures of family ties: for example, for the mobility equation, an increase in one standard deviation of the variable "living with parents" leads to a decline of 0.002 of the mobility variable, which is equivalent to 6 percent of the average of this variable. The results for the other family values variables are very similar and can explain between 4 and 10 percent of the mean of the mobility variable. The effects of the family variables from the country of origin are of comparable magnitude for the unemployment variable and a bit smaller for wages (this could be due to the fact that since individuals do not move to stay close to their families they might decide to invest less in education to start with and have lower wages as a result).

\subsubsection{Evidence on attitudes toward labor market regulation}

We then look at the implication of inherited family values on the demand for regulation (Tables 5-8). In Table 5-7 we use the three questions from the GSS described above. Each regression controls for a quadratic in age, years of education, gender, income, employment and marital status, number of children and region fixed effects. ${ }^{32}$ Standard errors are clustered at the country of origin level. The results are highly consistent with the previous cross-country estimates. US immigrants coming from strong family ties countries tend to consider job security as a more important characteristic for a job. They are also more likely to believe that the government should save jobs or directly intervene to regulate wages. The effects are statistically significant and economically sizeable. A one standard

insurance.

${ }^{32}$ The publicly available version of the GSS provide only the region of residence as geographic identifier. 
deviation increase in the fraction of adult population living at home in the country of origin can explain 5 percent of the sample average of all the three different measures of desire for regulation. The effect is of sizable magnitude when compared to variables such as income or education. An increase in one standard deviation in the years of education can explain 10 percent of the sample average of the desire for regulation.

Table 8 reports the estimated average effect size (AES) for the three measures of regulation examined in Tables 5-7. We computed the AES following Kling, Liebman, Katz and Sanbonmatsu (2004). Let $\beta^{k}$ indicate the estimated family ties coefficient for outcome variable $k$ and $\sigma^{k}$ the standard deviation of outcome $k$. Then, the average effect size is equal to $\frac{1}{K} \sum_{k=1}^{K} \frac{\beta^{k}}{\sigma^{k}}$, where $K$ is the total number of outcome variables. To properly calculate the sample variance of the AES, the coefficient $\beta^{k}$ are jointly estimated in a seemingly unrelated regression framework. ${ }^{33}$ The AES estimates confirm the finding when examining the attitudes toward regulation separately: coming from a country where family ties are very strong is associated with more desire for labor market regulation among immigrants. The results are always significant at the 1 percent level, independently of the measure of family ties in the country of origin used.

\subsubsection{Robustness checks}

A potential concern with the estimates reported up to this point is that the measures of family ties are capturing some other country of origin characteristics (migrants coming from poorer countries or with a lower level of human capital could have a higher level of unemployment or lower wages for example). We test for the possibility of omitted variables by controlling for various country of origin characteristics in both the CPS and GSS estimates: in particular we include the level of GDP per capita (Tables B3-B6) and the level of human capital (Tables B7-B11) ${ }^{34}$, as measured by the average number of years of education (Barro-Lee (2010)). In order to take into account differences in ancestors' human capital, we include a measure of "ethnic human capital", given by the average education of the immigrant group to which each second generation immigrant belongs

\footnotetext{
${ }^{33}$ See Clingingsmith, Khwaja and Kremer (2009) for an alternative application and further details.

${ }^{34}$ The General Social Survey contains information on the level of education of the parents. We can therefore also control directly for this variable in our regressions. The results (reported in Table B11) are robust to the inclusion of parental human capital, despite the much smaller sample size.
} 
(Tables B12-B15). To construct this measure we use the 1970 census and calculate the average years of education for all individuals who are in between the ages of 25 and 44 and who were born in one of the countries of origin in our sample. We select individuals in this age range as this roughly corresponds to the age interval in which we would find the parents of individuals in our sample. The inclusion of other cross-country characteristics does not modify the relevance of family values on labor market outcomes and attitudes of second generation immigrants.

As a second robustness check, we test whether family values are more robustly related to labor market outcomes or attitudes than another more commonly used cultural variable, the level of trust in a country (Tables B16-B19). Knack and Keefer (1997) have found for example a positive correlation between trust and economic development. One may worry that the cross-country differences in family values are simply picking up on crosscountry differences in the level of trust. We measure trust using the following question in the World Values Survey: "Generally speaking, would you say that most people can be trusted or that most people cannot be trusted?". Our results survive the inclusion of trust as an alternative cultural value.

As a third check, we test the robustness of our results to the use of different samples. For the labor market outcomes, we have used the Current Population Survey, since this dataset is the closest in time to the data on family ties taken from the World Values Survey. We check if the results also hold when we use evidence from previous Censuses of 1940, 1960 and 1970 (Tables B20-B22). ${ }^{35}$ We run the regressions under the assumption that family values observed today have been fairly stable over time, so we assume that they did not change in the last 70 years or so. Our results are remarkably consistent with those found using the Current Population Survey: today as well as 70 years ago, immigrants coming from strong family ties societies tend to have lower mobility rates, lower wages and a higher level of unemployment.

If differences in cultural values regarding the role of the family are relevant in explaining labor market outcomes one would expect a stronger effect if both parents come from the same country: norms are more likely to be transmitted if parents share the same cultural origin. We test whether this is the case by restricting the sample to second

\footnotetext{
${ }^{35}$ The Census 1950 does not contain the variable on geographical mobility.
} 
generation immigrants whose parents came from the same country (Tables B23-B25). We indeed find that the coefficients are more precisely estimated and larger in magnitudes ${ }^{36}$.

\section{Persistence}

One of the basic messages of the present paper is that labor market institutions depend upon deeply rooted cultural values, like family ties. Thus labor market institutions are persistent to the extent that family values are fairly constant over time. In this section we present evidence showing that indeed family values do not change quickly. We do so in two ways. First, we show that the strength of family ties inherited from countries of origin before 1940 is correlated with the stringency of labor market regulation in the countries of origin at the beginning of the 21st century. Second, we exploit differences in family types across European regions dating back to the Middle Ages, by using the classification by Todd (1990). We match historical family types with current individual family structures to show a strong persistence between family structures in the Middle Ages and family structures today. We also link historical family types to the demand for job regulation using the regional variation provided by Todd. We find strong evidence of persistence between historical family structures and current family structures, and between historical family structures and the demand for regulation. We cannot link immigrants' outcomes and preferences to the medieval classification of Todd, because the CPS and the GSS do not report region of origin of the immigrants.

\subsection{Values inherited before 1940 and 21st century institutions}

In this section, we investigate the persistence of family values and their long lasting impact on labor market regulations, by showing that attitudes toward the family of immigrants arrived in the US before 1940 are related to labor market regulations in the country of origin at the beginning of the twenty first century. We focus on family values before World War II since the main labor market institutions have been implemented in the post-war period.

The strength of family ties before World War II cannot be observed directly, since

\footnotetext{
${ }^{36}$ This exercise can be done only using the CPS. The Census contains information only about the country of origin of the father. The GSS asks to indicate only one country of ancestry.
} 
there is no survey available on this period. To track back historical values of family ties in different countries, we follow Algan and Cahuc (2010) methodology by estimating the inherited component of family values. More precisely, we estimate the family values that US immigrants have inherited from their forbears who migrated from different countries. To reconstruct those family values before World War II, we focus on U.S. immigrants whose ancestors arrived in the U.S. before 1940. The estimation of inherited family values is based on the GSS, which provides information on contemporaneous family values of US descendants of immigrants and the wave of immigration. To measure inherited family values, we run OLS regression of family values reported in the GSS on countries of origin fixed effects, in addition to individual characteristics. The inherited family values correspond to the coefficients of country of origin fixed effects. ${ }^{37}$

The GSS does not contain the same variables on family ties as those of the World Values Survey. To measure the strength of family ties we use the following variable: "How often do you spend a social evening with relatives?". The respondent can answer: "almost every day, once or twice a week, several times a month, about once a month, several times a year, about once a year, never". The answer has been coded from 1 to 7 so that a higher frequency of meetings with relatives corresponds to stronger family ties".

Figure 7 shows the correlation between the inherited family ties from the countries of origin before 1940 and the current family ties in the home countries. The strength of family ties for immigrants arrived before 1940 corresponds to the country of origin fixed effects in the microregressions on family ties in the GSS. The current family ties in the home country correspond to the share of adults still living in the parental house from the WVS. The correlation is rather steady and equal to 0.48 , showing that there is a strong inertia in family values across countries. In the appendix (Table B26) we show additional regressions documenting the strong correlations between reported family values in the GSS and home country family values based on the various measures from the WVS. Independently of how family ties are measured the correlations are very strong. This is a reassuring test for our empirical strategy and an additional confirmation of cultural

\footnotetext{
${ }^{37}$ The sample is made up of US immigrants whose ancestors migrated before 1940. If we assume a gap of 25 years between generations, this include the following sample of US immigrants: i) second generation immigrants born before 1940, since their parents immigrated in the U.S. before 1940; ii) third generation immigrants born before 1965, since their grand parents arrived in the U.S. before 1940; iii) fourth generation immigrants born before 1990 .
} 
transmission of family values across generations.

We next discuss the correlation between inherited family ties and current labor market legislations in the home countries. Table 9 shows the OLS estimations controlling for legal origin and population density. The correlation between firing costs in the 2000s and family values prior to 1940 is statistically significant at the 5 percent level. The correlation between the minimum wage legislation and past family values is also statistically significant at the 5 percent level. In contrast, neither legal origins nor population density are statistically significantly correlated with the regulation of labor when we include inherited family values. Moreover, the coefficients associated with past family values are of the same order of magnitude as the ones found with contemporaneous family values in Table B2, suggesting the long lasting effect of family ties on the design of labor market regulation.

\subsection{Medieval family structures and current desire for labor mar- ket regulation}

In this section we make a step further by suggesting that family values may be persistent over centuries not only decades. We document a correlation between medieval family structures and current family arrangements. In addition, we also show that medieval family structures are related to current desire for regulation. To do so, we use Todd's (1990) classification of medieval families, which is particularly appealing since it provides regional variation in the structure of the family. By linking the regional variation in family structures to individual desire for regulation, we further prove that the desire for regulation is not driven by other omitted cross country characteristics, since we will be able to control for country fixed effects.

Todd (1990) provides a characterization of family types along two dimensions. The first one refers to the vertical relationship between parents and children. The relationship is said to be "liberal" if children become independent from their parents at an early age and leave their parental home as soon as they get married. The relationship is said to be "authoritarian" if children continue to depend on their parents in adult age and still live with them after marrying. The second principle of organization of the family is the horizontal relationship between siblings, based on inheritance laws or practices. The 
relationship is egalitarian if siblings receive roughly an equal share of the family wealth after parents' death. On the other hand, the relationship is not egalitarian when the parents can favor one offspring at the expense of the others and transmits family wealth to a single targeted child only.

The combination of these four different patterns of family organization leads to define four family types. The absolute nuclear family, characterized by a liberal relationship between parents and children and by unequal inheritance rules. In this context, children become totally independent from their parents when they become adult and form single families with one couple and their children. The egalitarian nuclear family, with liberal relationship between parents and children and egalitarian inheritance rules among the children. According to Todd, this family type encourages stronger relations between the family members than the absolute nuclear family, at least until parents' death. The presence of egalitarian inheritance rules therefore encourages the co-residence of different generations, despite the liberal relationship between parents and children. The extended family, characterized by an authoritarian vertical relationship and an inegalitarian horizontal relationship between the siblings. The household consists of extended families, where the eldest child and his family stay in the parental home and inherit the family wealth, while the other children remain in the parental home only until they get married. ${ }^{38}$ The fourth type is the communitarian family, with both authoritarian vertical relationship and egalitarian inheritance rules between the sons. This type consists of large extended families, with all sons living with their wives in the parental house. ${ }^{39}$

For the case of Europe, Todd provides data at the regional level. There is a significant heterogeneity in family types across European countries. Figure 8 in Appendix shows the different family types at the regional level, using the original Todd's classification. ${ }^{40}$ Absolute nuclear families are more widespread in England, while in Southern European

\footnotetext{
${ }^{38}$ Todd refers to the extended family as stem family. He also refers to the imcomplete stem family, the same as the stem family but with more egalitarian inheritance rules (in principle but rarely in practice). We group together the complete and incomplete stem families in our quantitative analysis.

${ }^{39}$ Todd's family classification is based on historical monographies dating back to the Middle Ages, in different regions of Western European countries. These monographies were collected by the church or different legal powers to track their local population and levy taxes. Todd combined these historical monographies with census data in the 1950s and found a very strong persistence of the family arrangement across European regions since the Middle Ages.

${ }^{40}$ See Todd (1990) and Duranton et al. (2009) for a detailed presentation of the regional variation for Europe.
} 
countries, families are egalitarian nuclear, extended or communitarian. There is a fair amount of heterogeneity within the same country. In Northern countries like Denmark, Norway or Ireland, we see a division between nuclear egalitarian and extended families. In France, the region Ile de France and the North have egalitarian nuclear families, the West and the East are mainly populated by extended families, whereas communitarian families are the predominant family structures in the South East. The same heterogeneity is at work in countries like Spain, Portugal, Italy, Switzerland or Germany. Todd suggests that the long-term persistence of these family types could explain key economic outcomes such as the European industrial revolutions or the current economic development of regions. ${ }^{41}$

We complement the analyses of Todd (1990) and Duranton et al. (2009) by looking at the relationship between family types in the Middle Ages and the demand for job protection at end of the 20th century; we also look at the correlation between current family arrangements and medieval family structures using individual data from the World Values Survey. We match Todd's European classification of family types with the European countries of the World Values Survey and the International Social Survey Program (ISSP) ${ }^{42}$ datasets at the regional level. Note that Todd's data are available only on a map and the region he used do not necessarily correspond to the regional classification reported in the World Value Survey or the ISSP. For that reason we did a country by country adjustment overlaying Todd's original map with the classification of the WVS and ISSP.

We first document a correlation between the probability that an individual lives at their parents' home and medieval family structures. As outlined above, with the exception of absolute nuclear families, all the other family structures were favouring the cohabitation of parents and children. From the WVS, we also look at a question on the preference for job security: "Here are some more aspects of a job that people say are important. Please look at them and tell me which ones you personally think are important in a job?: Good Job Security?" The answers take on the value 1 if job security is mentioned and zero otherwise. We then consider a question taken from the ISSP on labor market regulation. In particular the question is: "Here is a list of potential government actions

\footnotetext{
${ }^{41}$ See Duranton et al. (2009) for details.

${ }^{42}$ The ISSP is a compilation of surveys, covering all OECD and Eastern European countries, devoted each year to different specific topics such as religion, social networks or the role of government. A specific ISSP survey on "The role of government" was carried out in 1996.
} 
for the economy: Help Declining Industries and Protect Jobs" and it is coded on a scale from 1 (strongly agree) to 4 (strongly disagree). The question is recoded so that a higher number means more regulation.

Table 10 (column 1) shows the correlation between Todd's family classification and the probability for a young adult to live at home with parents. We identify the relation across regions by including country fixed effects, while still controlling for individual characteristics. Controls included in the regression are gender, a quadratic in age, education, income, unemployment status, political orientation, religious denomination and country fixed effects. We include one dummy for each family type: absolute nuclear, egalitarian nuclear, extended and communitarian. Absolute nuclear family is the reference group. We find that the probability that individuals live with their parents in significantly higher in regions where the absolute nuclear family was not the dominant type in the Middle Ages. This is consistent with Todd (1990) and also Duranton et al. (2009). The latter study the correlation with average household size in 2000, measured as the number of individuals per household.

As a second step, we look at the relationship between medieval family structure and the contemporaneous desire for regulation (columns 2 and 3). Individuals coming from extended or communitarian family regions tend to be more pro job security than individuals from nuclear family. The effect of extended family and communitarian family on the demand for job security is statistically significant at the 5 percent level, while the relationship with nuclear family is not. Column 3 shows that individuals coming from regions where the family structure was prevalently communitarian also tend to be more supportive of government intervention than individuals coming from nuclear family. The results are statistically significant at the 5 percent level.

Overall all these results are in line with the prediction of the model according to which family values have persistent effects on labor market regulation if the intergenerational transmission of family values is sufficiently strong. Labor market regulations seem to have deep cultural roots since labor market rigidities at the beginning of the twenty first century are correlated with family values prevailing before WWII. We also find evidence of persistence not only between family structures in the Middle Ages and today, but also between medieval family structure and desire for labor market regulation today. 


\section{Conclusions}

Labor market deregulation requires geographical mobility, otherwise firms can take advantage of the immobility of workers and extract rents. However, geographical mobility requires relatively weak family ties. That is, individuals should not experience a too high utility loss if they need to move away from their family of origin. Such costs may, instead, be high in cultures that value family ties, and therefore family closeness. As a result countries with strong family ties rationally favor a host of labor market regulations, in order to restrict the monopsony power of firms. Family values may evolve over time, although slowly. In places with laissez-faire labor markets, parents have an incentive to teach children the benefits of mobility. In countries with regulated labor markets, the benefit of mobility are much lower and parents can, if they choose to do so, teach the value of family ties, since they come at lower or no costs. Thus we can have two equilibria with a two way causality between family ties and labor market regulation.

We investigate this correlation between family values and attitudes toward labor market regulation and preferences for job security versus free labor market with cross country evidence, individual level evidence drawn from immigrants in the US, together with evidence about persistence in family structures going back to the Medieval period. In all cases we found rather strong confirmation of a correlation between labor market institutions and desire for regulation, and differences in family values/structures. The correlation between labor market regulation and relatively slow moving cultural traits regarding the family, and the fact that labor market regulation is complementary to certain family values, explain the difficulty in liberalizing labor markets. In a sense the relatively low employment and inefficiency associated with labor market regulation is the price that certain countries choose to pay in order to enjoy the benefits of family ties and closeness.

\section{References}

[1] Aghion P., Algan, Y. and Cahuc, P., 2011, "Civil Society and the State? The interplay between Cooperation and Minimum Wage Regulation", Journal of the European Economic Association, 9(1): 3-42. 
[2] Aghion P., Algan, Y., Cahuc, P. and Shleifer, A., 2010, "Regulation and Distrust", Quarterly Journal of Economics, 125(3): 1015-1049.

[3] Alesina, A. and Angeletos, G-M., 2005, "Fairness and Redistribution", American Economic Review, 95(5): 960-980.

[4] Alesina, A. Cozzi, G. and Manotovan, N., 2009, "The evolution of, Ideology, Fairness and Redistribution" NBER WP 15587

[5] Alesina, A. and Fuchs-Schündeln, N., 2007, "Good-Bye Lenin (or Not?): The Effect of Communism on People's Preferences", American Economic Review, 97(4):15071528.

[6] Alesina A. and P. Giuliano, 2011, Family Ties and Political Particicpation, Journal of the European Economic Association, forthcoming

[7] Alesina, A. and Giuliano P., 2010, The Power of Family, Journal of the Economic Growth, vol. 25(2), 93-125

[8] Alesina, A. and Glaeser, E., 2004, Fighting Poverty in the US and Europe, Oxford, UK: Oxford University Press.

[9] Algan, Y. and Cahuc, P., 2005, "The Roots of Low European Employment: Family Culture?", in NBER International Seminar on Macroeconomics 2005, Pissarides, C. and Frankel, J. (eds), Cambridge, MIT Press.

[10] Algan, Y. and Cahuc, P., 2009, "Civic Virtue and Labor Market Institutions", American Economic Journal: Macroeconomics, 1(1): 111-145.

[11] Algan, Y. and Cahuc, P., 2010, "Inherited Trust and Growth", American Economic Review, 100: 2060-2092.

[12] Antecol, H., 2000, "An Examination of Cross-Country Differences in the Gender Gap in Labor Force Participation Rates", Labour Economics, 7: 409-426.

[13] Barro, R. and J.W. Lee, 2010, "A New Data Set of Educational Attainment in the World, 1950-2010", NBER WP 15902. 
[14] Belot, M. and Ermisch, J., 2006, "Friendship ties and geographical mobility, evidence from the BHPS", ISER Working Paper 2006-33. Colchester: University of Essex.

[15] Bentolila, S. and Ichino, A., 2008, "Unemployment and Consumption Near and Far Away From the Mediterranean", Journal of Population Economics, 21: 255-280.

[16] Bisin, A., Patacchini, E., Verdier, T. and Zenou, Y., 2006, "Bend It Like Beckham: Identity, Socialization, and Assimilation", CEPR working paper 5652.

[17] Bisin, A., Topa, G. and Verdier, T., 2004, "Religious Intermarriage and Socialization in the US", Journal of Political Economy, 112: 615-665.

[18] Bisin, A. and Verdier, T. 2000, "Beyond the Melting Pot: Cultural Transmission, Marriage and the Evolution of Ethnics and Religious Traits", Quarterly Journal of Economics, 115(3): 955-988.

[19] Bisin, A. and Verdier, T., 2001, "The Economics of Cultural Transmission and the Dynamics of Preferences", Journal of Economic Theory, 97: 298-319.

[20] Blanchard, O. and Giavazzi, F., 2003, The Macroeconomic Effects of Regulation and Deregulation in Goods and Labor Markets", Quarterly Journal of Economics, 118(3): 879-909.

[21] Blanchard O and L. Katz, 1992, "Regional Evolutions" Brookings papers on Economic Activity, 1-75.

[22] Blanchard O. and J. Wolfers, 2000, "The Role of Shocks and Institutions in the Rise of European Unemployment" Economic Journal, vol 110, no. 462: C1-C33

[23] Borjas, G., 1992, "Ethnic Capital and Intergenerational Mobility", Quarterly Journal of Economics, vol 107(1): 123-150.

[24] Borjas, G., 1995, "Ethnicity, Neighborhoods, and Human-Capital Externalities", American Economic Review, vol 85(3): 365-390.

[25] Botero, J., Djankov, S., La Porta, R., Lopez-de-Silanes, F. and Shleifer, A., 2004, "The Regulation of Labor", Quarterly Journal of Economics, 119(4): 1339-82. 
[26] Carroll, D., Rhee, C. and Rhee, B., 1994, "Are There Cultural Effects on Saving? Some Cross-Sectional Evidence", Quarterly Journal of Economics, 109(3): 685-700.

[27] Clingingsmith, D., Khwaja A. and M. Kremer, 2009, "Estimating the Impact of the HAjj: Religion and Tolerance in Islam's Global Gathering", Quarterly Journal of Economics, 124 (3), 1133-1170.

[28] David, Q., Janiak, Q. and Wasmer, E., 2009, "Local social capital and geographical mobility", Journal of Urban Economics, 68 (2), 191-204.

[29] Duranton, G., Rodríguez-Pose, A. and Sandall, R., 2009, "Family types and the persistence of regional disparities in Europe", Economic Geography, 85(1): 23-47.

[30] Eichhorst, W., Feil, M., Braun, C., 2008, "What Have We Learned? Assessing Labor Market Institutions and Indicators", IZA DP 3470.

[31] Fernandez, R. and A. Fogli, 2006, "Fertility: The Role of Culture and Family Experience", Journal of the European Economic Association Papers and Proceedings, 4(2-3): 552-561.

[32] Fernandez, R. and A. Fogli, 2009, "Culture: An Empirical Investigation of Beliefs, Work and Fertility", American Economic Journal: Macroeconomics, 1(1): 146-177.

[33] Freeman, R., 2008, "Labor market institutions around the world", Handbook of Industrial and Employment Relations, Bacon, N., Blyton, P., Fiorito, J., and Heery, E. (eds). London: Sage, pp. 640-659.

[34] Galasso, V. and P. Profeta, 2010, "When the State Mirrors the Family: The Design of Pension Systems", CESIFO WP 3191.

[35] Giavazzi, F., Schiantarelli, F. and Serafinelli, M., 2009, "Culture, Policies and Labor Market Outcomes", NBER WP 15417

[36] Giuliano, P. , 2007, "Living Arrangements in Western Europe: Does Cultural Origin Matter?", Journal of the European Economic Association, 5(5): 927-952.

[37] Glaeser, E., David Laibson, D. and Sacerdote, B., 2002, An Economic Approach to Social Capital, The Economic Journal, 112, pp. F437-F458. 
[38] Glaeser, E., and Redlick, C., 2008, "Social Capital and Urban Growth", NBER WP 14374 .

[39] Guiso, L., Sapienza, S. and Zingales, L., 2006, "Does Culture Affect Economic Outcomes?", Journal of Economic Perspectives, 20(2): 23-48.

[40] Guiso, L., Sapienza, P. and Zingales, L., 2008, "Social Capital as Good Culture", Journal of the European Economic Association Papers and Proceedings, 6(2-3): 295320

[41] Guiso, L., Sapienza, P. and Zingales, L., 2009, "Cultural Biases in Economic Exchange?", Quarterly Journal of Economics, 124(3): 1095-1131.

[42] Guttman J., 2001a, "Self enforcing reciprocity norms and intergenerational transfers: theory and evidence" Journal of Public Economics, 81, 117-151

[43] Guttman J., 2001b, " Family, markets and self enforcing reciprocity norms", Annales d Economie et de Statistique 63-64, 89-110

[44] Guttman J. and N. Yacouel, 2007, "On the Expansion of the Market and the Decline of the Family" Review of Economics of the Household, 5, 1-13.

[45] Hassler, J., J. Rodriguez Mora, K. Storesletten and F. Zilibotti (2005), "A Positive Theory of Geographic Mobility and Social Insurance", International Economic Review, vo. 46 (1), 263-302.

[46] Knack, S. and P. Keefer, "Does Social Capital Have an Economic Payoff? A CrossCountry Investigation", 1997, Quarterly Journal of Economics, 112 (4): 1251-1288.

[47] La Porta, R., Lopez-de-Silanes, F. and Shleifer, A., 2008, "The Economic Consequences of Legal Origins", Journal of Economic Literature, 46(2):285-332.

[48] Lindbeck A. and D. Snower, 1989, The Insider Outsider Theory of Unemployment MIT Press Cambridge Mass

[49] Luttmer, E. and Singhal, M., 2009, "Culture, Context, and the Taste for Redistribution," NBER WP 14268. 
[50] Mullingan, C. and Shleifer, A., 2005, "The Extent of the Market and the Supply of Regulation", Quarterly Journal of Economics.

[51] Patacchini, E. and Zenou, Y., 2007, "Intergenerational Education Transmission: Neighborhood Quality and/or Parents' Involvement?", CEPR DP 4744.

[52] Pissarides, C., 2000, Equilibrium Unemployment Theory, MIT Press.

[53] Reher, D., 1998, "Family Ties in Western Europe: Persistent Contrasts", Population and Development Review, XXIV, 203-234.

[54] Saint-Paul, G., 2000, The Political Economy of Labour Market Institutions, Oxford University Press.

[55] Saint-Paul, G., 2002, The Political Economy of Employment protection, Journal of Political Economy, 110(3), 672-704.

[56] Spilimbergo, A. and Ubeda, L., 2004a, "A model of multiple equilibria in geographic labor mobility", Journal of Development Economics, 73(1): 107-123

[57] Spilimbergo, A. and Ubeda, L., 2004b, "Family Attachment and the Decision to Move by Race", Journal of Urban Economics, 55(3): 478-497.

[58] Tabellini, G., 2008a, "Institutions and Culture", Journal of the European Economic Association Papers and Proceedings, vol.6(2-3): 255-294.

[59] Tabellini, G., 2008b, "The Scope of Cooperation: Norms and Incentives", Quarterly Journal of Economics, vol 123(3), pp. 905-950.

[60] Todd, E., 1990, L'invention de l'Europe. Paris: Seuil.

[61] Zorlu, A., 2009, "Who Leaves the City? The Influence of Ethnic Segregation and Family Ties", Population, Space and Place, 15 (4): 323-342. 
Figure 1

The relation between the gains $\Gamma(\sigma)$ to choose strong family ties rather than weak family ties and the share $\sigma$ of individuals with strong family ties

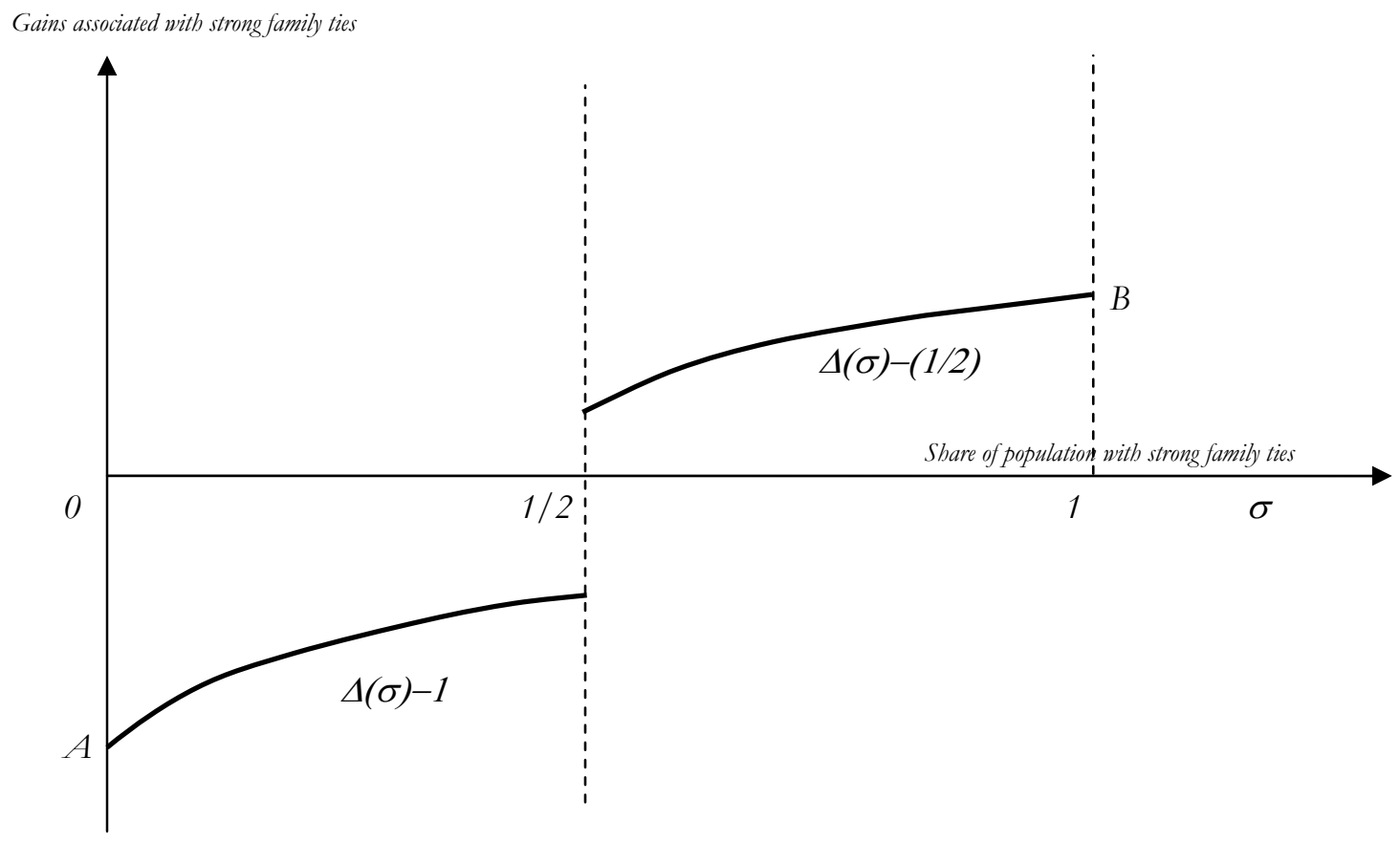

Figure2

Preferred equilibrium in the $(\Delta(1), c)$ plane: regulation is preferred in the area above the thick curve

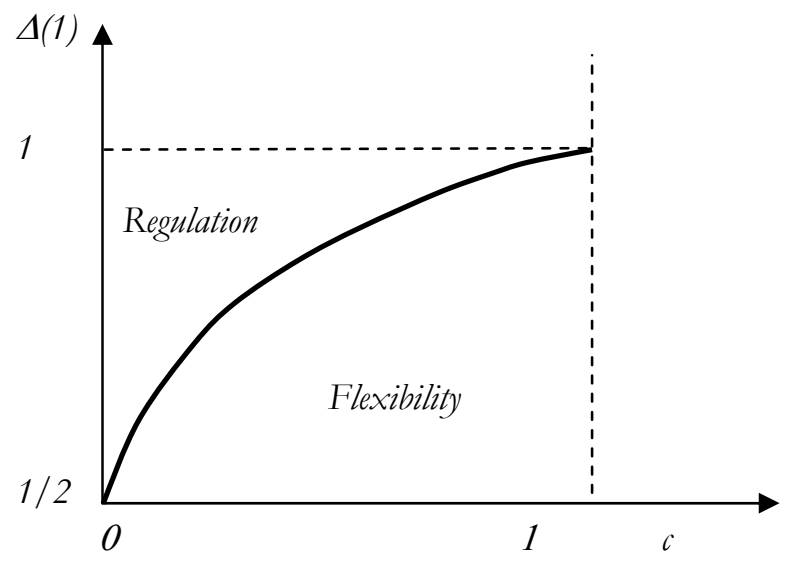


Figure 3

Labor Market Regulation and Family Ties

\section{Labor market regulation and family ties}
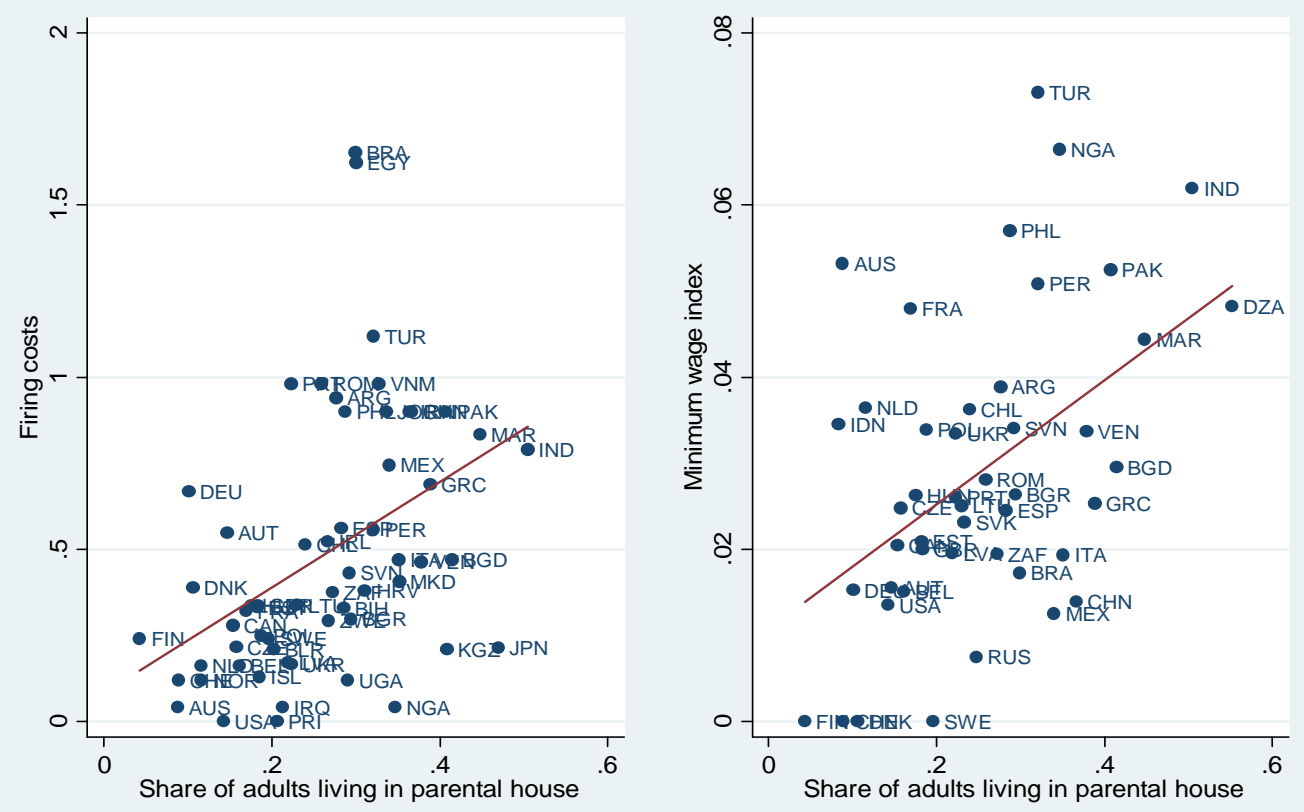

Figure 4

Desire for Labor Market Regulation and Family Ties

Desire for labor market regulation and family ties
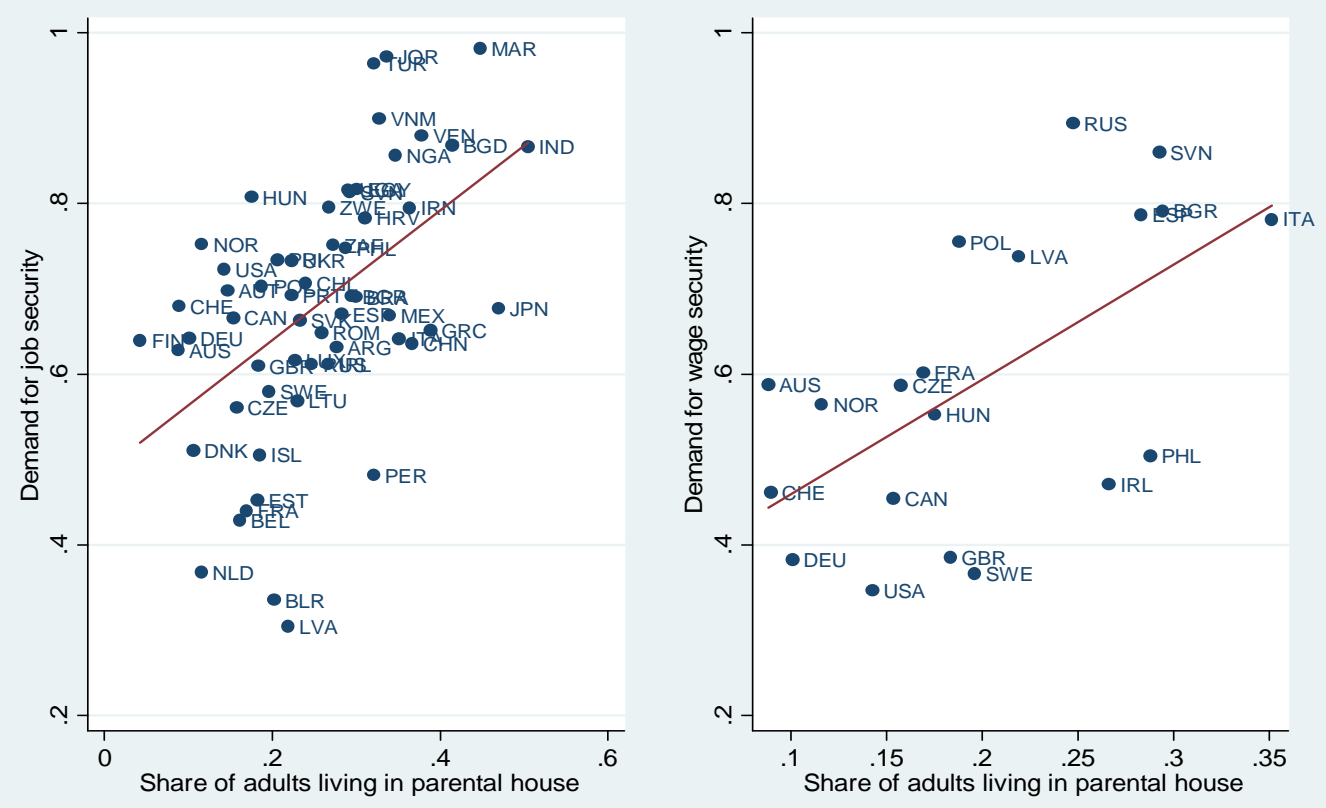
Figure 5

Labor market regulation and additional measures of family ties

Labor market regulations and family ties
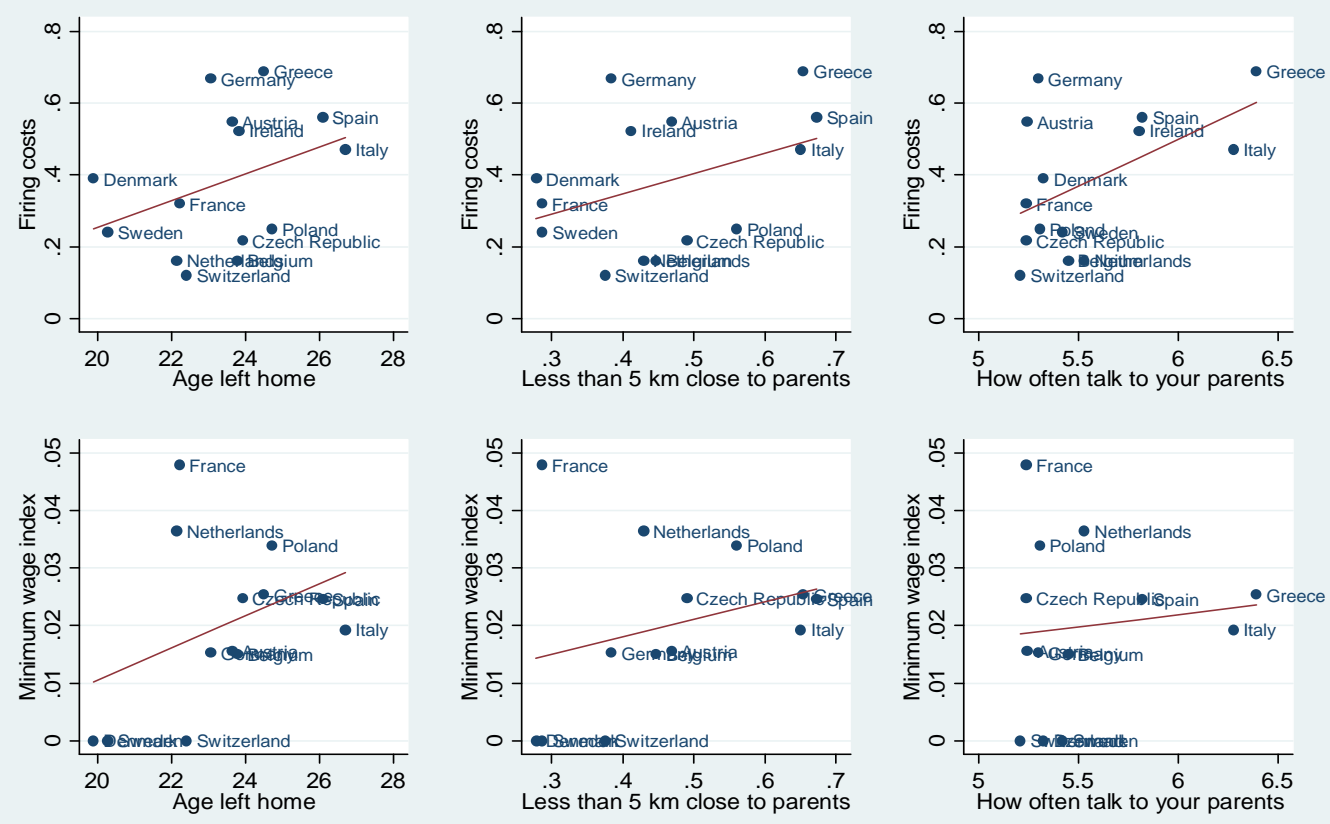

Figure 6

Desire for labor market regulation and additional measures of family ties

Desire for labor market regulations and family ties
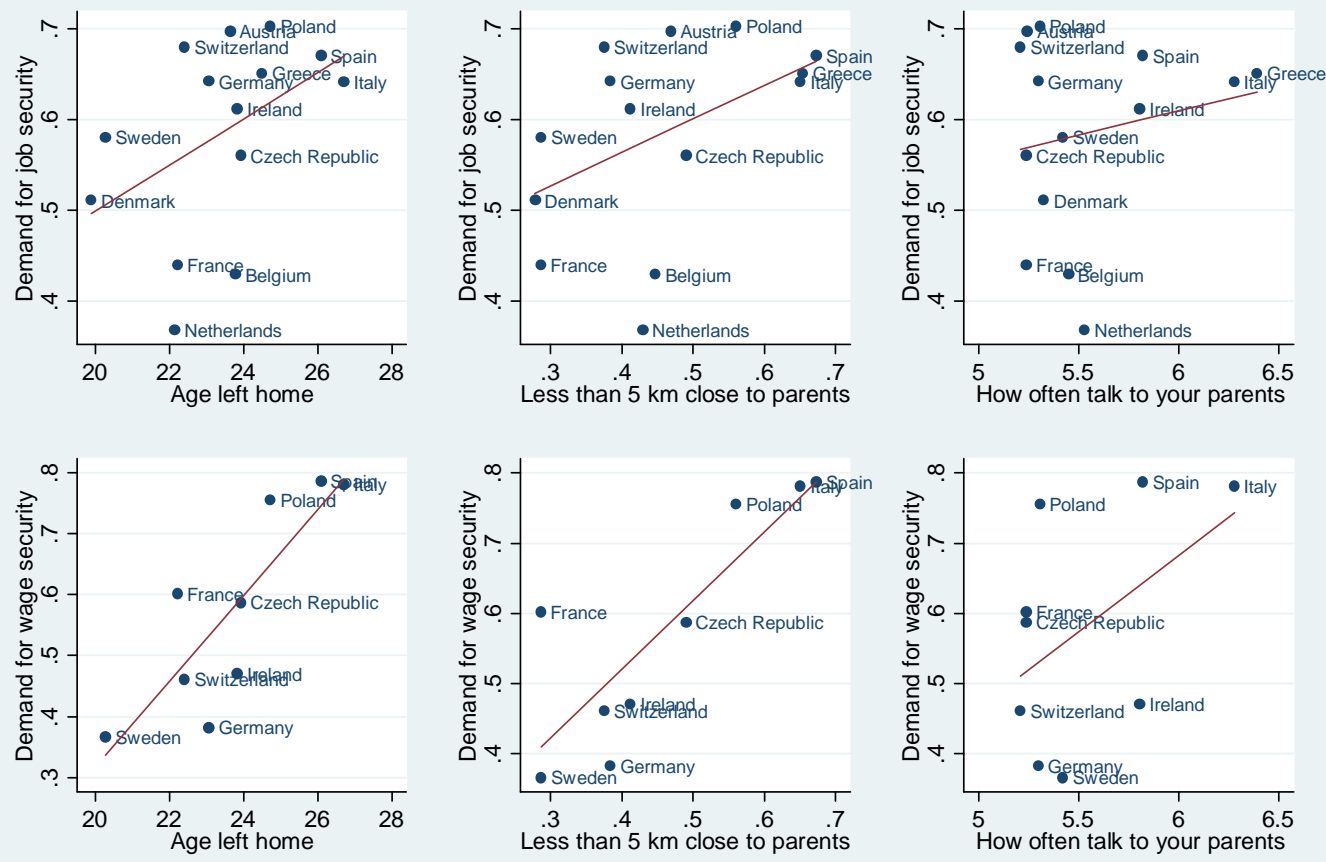
Figure 7

Correlation between inherited family ties and family ties in the home country

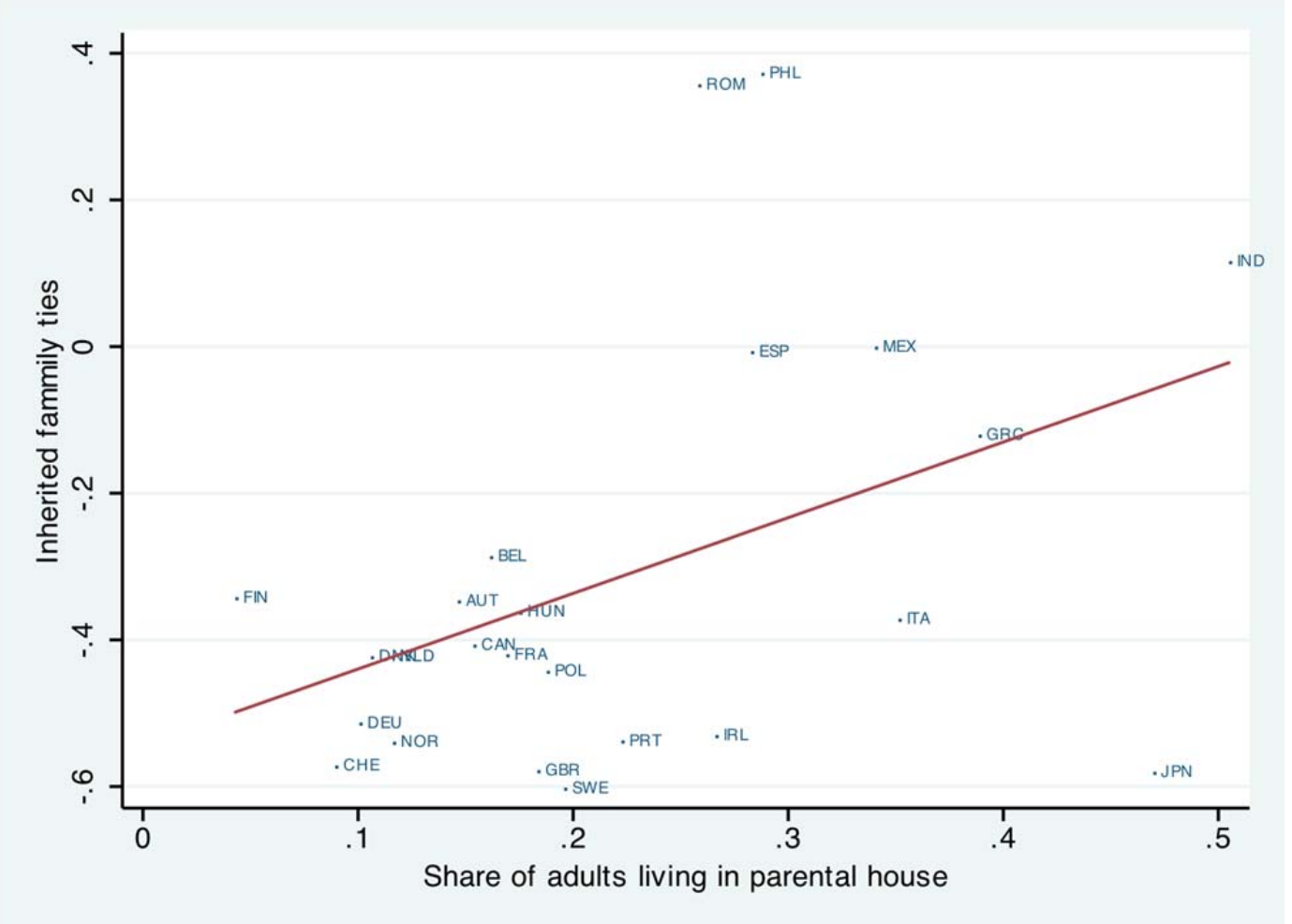

Source: Share of adults living in parental house: WVS. Inherited family ties: GSS. Inherited family ties are the conditional average frequency of contacts with relatives by country of origin of US immigrants. Reference country of origin: Mexico 
Table 1

Pair-wise correlations between objective and subjective measures of family ties

\begin{tabular}{|c|c|c|c|c|c|c|}
\hline Share of adult pop. in parent. home & $\begin{array}{c}\text { Share of adult pop. } \\
\text { in parental home } \\
1\end{array}$ & $\begin{array}{c}\text { Parents' } \\
\text { Responsibility }\end{array}$ & $\begin{array}{l}\text { Respect } \\
\text { parents }\end{array}$ & Obedience & $\begin{array}{l}\text { Family } \\
\text { important }\end{array}$ & $\begin{array}{l}\text { Parents } \\
\text { proud }\end{array}$ \\
\hline Parents' respons. & $\begin{array}{c}0.68 \\
(0.00)\end{array}$ & 1 & & & & \\
\hline Respect parents & $\begin{array}{c}0.17 \\
(0.13)\end{array}$ & $\begin{array}{c}0.27 \\
(0.02)\end{array}$ & 1 & & & \\
\hline Obedience & $\begin{array}{c}0.34 \\
(0.00)\end{array}$ & $\begin{array}{c}0.43 \\
(0.36)\end{array}$ & $\begin{array}{c}0.66 \\
(0.00)\end{array}$ & 1 & & \\
\hline Family import. & $\begin{array}{c}0.26 \\
(0.02)\end{array}$ & $\begin{array}{c}0.36 \\
(0.00)\end{array}$ & $\begin{array}{c}0.49 \\
(0.00)\end{array}$ & $\begin{array}{c}0.38 \\
(0.00)\end{array}$ & 1 & \\
\hline Parents proud & $\begin{array}{c}0.57 \\
(0.00)\end{array}$ & $\begin{array}{c}0.77 \\
(0.00)\end{array}$ & $\begin{array}{c}0.46 \\
(0.00)\end{array}$ & $\begin{array}{c}0.66 \\
(0.00)\end{array}$ & $\begin{array}{c}0.51 \\
(0.00)\end{array}$ & 1 \\
\hline
\end{tabular}

P-values in parenthesis

Table 2

Family Ties and Mobility

Second Generation Immigrants, CPS 1994-2012. Microestimates

\begin{tabular}{|c|c|c|c|c|c|c|}
\hline & $\begin{array}{c}(1) \\
\text { Mobility }\end{array}$ & $\begin{array}{c}(2) \\
\text { Mobility }\end{array}$ & $\begin{array}{c}(3) \\
\text { Mobility }\end{array}$ & $\begin{array}{c}\text { (4) } \\
\text { Mobility }\end{array}$ & $\begin{array}{c}(5) \\
\text { Mobility }\end{array}$ & $\begin{array}{c}(6) \\
\text { Mobility }\end{array}$ \\
\hline Share of adult pop. in parent. home & $\begin{array}{c}-0.021^{* *} \\
(0.011)\end{array}$ & & & & & \\
\hline Respect parents & & $\begin{array}{c}-0.028^{* * *} \\
(0.010)\end{array}$ & & & & \\
\hline Obedience & & & $\begin{array}{c}-0.015^{*} \\
(0.008)\end{array}$ & & & \\
\hline Parents proud & & & & $\begin{array}{l}-0.007 * \\
(0.004)\end{array}$ & & \\
\hline Parents responsibility & & & & & $\begin{array}{l}-0.009 \\
(0.008)\end{array}$ & \\
\hline Family important & & & & & & $\begin{array}{c}-0.037 * * * \\
(0.012)\end{array}$ \\
\hline Number of countries & 71 & 71 & 75 & 74 & 71 & 71 \\
\hline Observations & 82926 & 105181 & 84571 & 84289 & 105149 & 105320 \\
\hline
\end{tabular}


Table 3

Family Ties and Unemployment

Second Generation Immigrants, CPS 1994-2012. Microestimates

\begin{tabular}{|c|c|c|c|c|c|c|}
\hline & $\begin{array}{c}\text { (1) } \\
\text { Unempl. }\end{array}$ & $\begin{array}{c}\text { (2) } \\
\text { Unempl. }\end{array}$ & $\begin{array}{c}\text { (3) } \\
\text { Unempl. }\end{array}$ & $\begin{array}{c}\text { (4) } \\
\text { Unempl. }\end{array}$ & $\begin{array}{c}\text { (5) } \\
\text { Unempl. }\end{array}$ & $\begin{array}{c}\text { (6) } \\
\text { Unempl. }\end{array}$ \\
\hline Share adult pop. in parent. home & $\begin{array}{c}0.013 \\
(0.018)\end{array}$ & & & & & \\
\hline Respect parents & & $\begin{array}{c}0.048^{* * *} \\
(0.015)\end{array}$ & & & & \\
\hline Obedience & & & $\begin{array}{c}0.041 * * * \\
(0.010)\end{array}$ & & & \\
\hline Parents proud & & & & $\begin{array}{c}0.020^{* * *} \\
(0.004)\end{array}$ & & \\
\hline Parents responsibility & & & & & $\begin{array}{c}0.042^{* * *} \\
(0.011)\end{array}$ & \\
\hline Family important & & & & & & $\begin{array}{c}0.071 * * * \\
(0.015)\end{array}$ \\
\hline Number of countries & 71 & 71 & 75 & 74 & 71 & 71 \\
\hline Observations & 52982 & 67665 & 54117 & 53954 & 67658 & 67758 \\
\hline
\end{tabular}

\section{Table 4}

Family Ties and Log Hourly Wages

Second Generation Immigrant, CPS 1994-2012. Microestimates

\begin{tabular}{|c|c|c|c|c|c|c|}
\hline & $\begin{array}{c}(1) \\
\text { Log wages }\end{array}$ & $\begin{array}{c}(2) \\
\text { Log wages } \\
\end{array}$ & $\begin{array}{c}(3) \\
\text { Log wages } \\
\end{array}$ & $\begin{array}{c}\text { (4) } \\
\text { Log wages } \\
\end{array}$ & $\begin{array}{c}(5) \\
\text { Log wages } \\
\end{array}$ & $\begin{array}{c}\text { (6) } \\
\text { Log wages }\end{array}$ \\
\hline Share adult pop. in parent. home & $\begin{array}{c}-0.189 * * * \\
(0.071)\end{array}$ & & & & & \\
\hline Respect parents & & $\begin{array}{c}-0.195^{* * *} \\
(0.071)\end{array}$ & & & & \\
\hline Obedience & & & $\begin{array}{c}-0.207 * * * \\
(0.062)\end{array}$ & & & \\
\hline Parents proud & & & & $\begin{array}{c}-0.089 * * * \\
(0.021)\end{array}$ & & \\
\hline Parents responsibility & & & & & $\begin{array}{c}-0.143 * * * \\
(0.046)\end{array}$ & \\
\hline Family important & & & & & & $\begin{array}{c}-0.300 * * * \\
(0.087)\end{array}$ \\
\hline Number of countries & 72 & 72 & 76 & 75 & 72 & 72 \\
\hline Observations & 60962 & 77983 & 62291 & 62137 & 78031 & 78158 \\
\hline R-squared & 0.27 & 0.27 & 0.27 & 0.27 & 0.27 & 0.27 \\
\hline
\end{tabular}




\section{Table 5}

Family Values and Demand for Labor Regulation: Importance of job security - GSS 1977-2010

\begin{tabular}{|c|c|c|c|c|c|c|}
\hline & $\begin{array}{c}\text { (1) } \\
\text { Job security }\end{array}$ & $\begin{array}{c}\text { (2) } \\
\text { Job security }\end{array}$ & $\begin{array}{c}\text { (3) } \\
\text { Job security }\end{array}$ & $\begin{array}{c}\text { (4) } \\
\text { Job security }\end{array}$ & $\begin{array}{c}\text { (5) } \\
\text { Job security }\end{array}$ & $\begin{array}{c}\text { (6) } \\
\text { Job security }\end{array}$ \\
\hline Share adult pop. in parent. home & $\begin{array}{c}0.807 * * * \\
(0.107)\end{array}$ & & & & & \\
\hline Respect parents & & $\begin{array}{c}0.631 * * * \\
(0.126)\end{array}$ & & & & \\
\hline Obedience & & & $\begin{array}{c}0.363^{* *} \\
(0.152)\end{array}$ & & & \\
\hline Parents proud & & & & $\begin{array}{c}0.234^{* * *} \\
(0.039)\end{array}$ & & \\
\hline Parents responsibility & & & & & $\begin{array}{c}0.537 * * * \\
(0.195)\end{array}$ & \\
\hline Family important & & & & & & $\begin{array}{c}0.616^{* *} \\
(0.234)\end{array}$ \\
\hline Number of countries & 29 & 28 & 29 & 23 & 28 & 29 \\
\hline Observations & 13977 & 13862 & 13977 & 11985 & 13954 & 13977 \\
\hline R-squared & 0.09 & 0.09 & 0.09 & 0.09 & 0.09 & 0.09 \\
\hline
\end{tabular}

Robust standard errors are clustered at the ancestry level. *** significant at $1 \%, * *$ significant at $5 \%, *$ significant at $10 \%$. Regressions control for a quadratic in age, education, income, marital and employment status, number of children, a gender dummy, region and year fixed effects. Family ties variables are measured in the country of origin from the WVS.

\section{Table 6}

Family Values and Demand for Labor Regulation: Government support for declining industries - GSS 1977-2010

\begin{tabular}{|c|c|c|c|c|c|c|}
\hline & $\begin{array}{c}(1) \\
\text { Save jobs }\end{array}$ & $\begin{array}{c}(2) \\
\text { Save jobs } \\
\end{array}$ & $\begin{array}{c}\text { (3) } \\
\text { Save jobs }\end{array}$ & $\begin{array}{c}\text { (4) } \\
\text { Save jobs }\end{array}$ & $\begin{array}{c}(5) \\
\text { Save jobs }\end{array}$ & $\begin{array}{c}(6) \\
\text { Save jobs }\end{array}$ \\
\hline Share adult pop. in parent. home & $\begin{array}{c}1.100^{* * *} \\
(0.259)\end{array}$ & & & & & \\
\hline Respect parents & & $\begin{array}{c}0.769 * * * \\
(0.225)\end{array}$ & & & & \\
\hline Obedience & & & $\begin{array}{c}0.430^{* *} \\
(0.209)\end{array}$ & & & \\
\hline Parents proud & & & & $\begin{array}{c}0.277^{* * *} \\
(0.084)\end{array}$ & & \\
\hline Parents responsibility & & & & & $\begin{array}{c}0.660^{* *} \\
(0.295)\end{array}$ & \\
\hline Family important & & & & & & $\begin{array}{l}0.725^{*} \\
(0.362)\end{array}$ \\
\hline Number of countries & 29 & 28 & 29 & 23 & 28 & 29 \\
\hline Observations & 3167 & 3140 & 3167 & 2711 & 3160 & 3167 \\
\hline R-squared & 0.12 & 0.12 & 0.11 & 0.12 & 0.11 & 0.11 \\
\hline
\end{tabular}




\section{Table 7}

Family Values and Demand for Labor Regulation:

Government should regulate wages - GSS 1977-2010

\begin{tabular}{|c|c|c|c|c|c|c|}
\hline & $\begin{array}{c}(1) \\
\text { Set wages }\end{array}$ & $\begin{array}{c}(2) \\
\text { Set wages }\end{array}$ & $\begin{array}{c}\text { (3) } \\
\text { Set wages }\end{array}$ & $\begin{array}{c}\text { (4) } \\
\text { Set wages }\end{array}$ & $\begin{array}{c}\text { (5) } \\
\text { Set wages }\end{array}$ & $\begin{array}{c}(6) \\
\text { Set wages }\end{array}$ \\
\hline Share adult pop. in parent. home & $\begin{array}{c}0.964^{* * *} \\
(0.243)\end{array}$ & & & & & \\
\hline Respect parents & & $\begin{array}{c}0.776^{* * *} \\
(0.208)\end{array}$ & & & & \\
\hline Obedience & & & $\begin{array}{c}0.427^{* *} \\
(0.204)\end{array}$ & & & \\
\hline Parents proud & & & & $\begin{array}{c}0.269 * * * \\
(0.072)\end{array}$ & & \\
\hline Parents responsibility & & & & & $\begin{array}{c}0.615^{* * *} \\
(0.220)\end{array}$ & \\
\hline Family important & & & & & & $\begin{array}{c}0.774 * * \\
(0.289)\end{array}$ \\
\hline Number of countries of origin & 29 & 28 & 29 & 23 & 28 & 29 \\
\hline Observations & 2145 & 2126 & 2145 & 1845 & 2139 & 2145 \\
\hline R-squared & 0.07 & 0.07 & 0.06 & 0.07 & 0.07 & 0.06 \\
\hline
\end{tabular}

Table 8

Family Values and Demand for Labor Regulation: Average Effect Size Coefficients - GSS 1977-2010

\begin{tabular}{|c|c|c|c|c|c|c|}
\hline & $\begin{array}{c}(1) \\
\text { AES }\end{array}$ & $\begin{array}{c}(2) \\
\text { AES }\end{array}$ & $\begin{array}{c}(3) \\
\text { AES }\end{array}$ & $\begin{array}{c}(4) \\
\text { AES }\end{array}$ & $\begin{array}{c}(5) \\
\text { AES }\end{array}$ & $\begin{array}{c}(6) \\
\text { AES }\end{array}$ \\
\hline Share adult pop. in parent. home & $\begin{array}{c}0.504 * * * \\
(0.106)\end{array}$ & & & & & \\
\hline Respect parents & & $\begin{array}{c}0.402 * * * \\
(0.092)\end{array}$ & & & & \\
\hline Obedience & & & $\begin{array}{c}0.269 * * * \\
(0.091)\end{array}$ & & & \\
\hline Parents proud & & & & $\begin{array}{c}0.121 * * * \\
(0.030)\end{array}$ & & \\
\hline Parents responsibility & & & & & $\begin{array}{c}0.373 * * * \\
(0.117)\end{array}$ & \\
\hline Family important & & & & & & $\begin{array}{c}0.456^{* * *} \\
(0.151)\end{array}$ \\
\hline Number of countries & 29 & 28 & 29 & 23 & 28 & 29 \\
\hline Observations & 6430 & 6376 & 6430 & 5514 & 6418 & 6430 \\
\hline $\begin{array}{l}\text { Robust standard errors are clustered } \\
\text { AES averages the normalized treatme } \\
\text { variable is one of the desire for reg } \\
\text { marital and employment status, num } \\
\text { measured in the country of origin fro } \\
\text { the regressions for the three attitude }\end{array}$ & $\begin{array}{l}\text { e ancestry } \\
\text { effects obta } \\
\text { ion measur } \\
\text { of childrer } \\
\text { the WVS. T } \\
\text { ables towar }\end{array}$ & $\begin{array}{l}\text { el. } * * * \text { sign } \\
\text { d from a s } \\
\text { All regressi } \\
\text { ender dum } \\
\text { number of } \\
\text { egulation. }\end{array}$ & $\begin{array}{l}\text { ant at } 1 \% \text {, } \\
\text { ingly unre } \\
\text { control } f \\
\text { s and regi } \\
\text { servations }\end{array}$ & $\begin{array}{l}\text { ignificant } \\
\text { d regressic } \\
\text { quadratic } \\
\text { ixed effec } \\
\text { he average }\end{array}$ & $\begin{array}{l}\%,{ }^{*} \text { signif } \\
\text { which eac } \\
\text { ge, educa } \\
\text { Family ties } \\
\text { mber of ob }\end{array}$ & $\begin{array}{l}\text { nt at } 10 \% . \\
\text { dependent } \\
\text { n, income, } \\
\text { riables are } \\
\text { rvations in }\end{array}$ \\
\hline
\end{tabular}




\section{Table 9}

Inherited Family Ties Before 1940 and Labor Regulation

\begin{tabular}{lcc}
\hline \hline Dependent variable & $\begin{array}{c}(1) \\
\text { Firing costs }\end{array}$ & $\begin{array}{c}(2) \\
\text { State regulation of } \\
\text { minimum wage }\end{array}$ \\
\hline Inherited family ties & $.554^{* *}$ & $.024^{* *}$ \\
before 1940 & $(.206)$ & $(.010)$ \\
Civil law origin & .001 & -.005 \\
Scandinavian origin & $(.142)$ & $(.009)$ \\
& -.158 & -.021 \\
German origin & $(.179)$ & $(.013)$ \\
& -.058 & -.007 \\
Ln(population) & $(.146)$ & $(.010)$ \\
& .002 & .003 \\
Observations & $(.043)$ & $(.002)$ \\
R-squared & 24 & 23 \\
\hline \hline
\end{tabular}

Source: GSS, ILO (2007) and Botero et al. (2004). The reference group for legal origin is common law. Robust standard errors in parentheses. *** significant at $1 \%, * *$ significant at $5 \%, *$ significant at $10 \%$.

\section{Table 10}

Family Ties, Desire for Regulation and Medieval Family Structure

\begin{tabular}{lccc}
\hline VARIABLES & $\begin{array}{c}(1) \\
\text { Living with } \\
\text { parents } \\
\text { (adult children) }\end{array}$ & $\begin{array}{c}(3) \\
\text { Most important } \\
\text { for a job: } \\
\text { job security }\end{array}$ & $\begin{array}{c}(2) \\
\text { Government: } \\
\text { help to } \\
\text { protect jobs }\end{array}$ \\
\hline Egalitarian Nuclear Family & $0.090^{* * *}$ & 0.090 & 0.12 \\
Extended Family & $(0.029)$ & $(0.08)$ & $(0.09)$ \\
Communitarian Family & $0.061^{* *}$ & $0.14 * *$ & 0.102 \\
& $(0.022)$ & $(0.06)$ & $(0.082)$ \\
Observations & $0.092^{* * *}$ & $0.15^{* *}$ & $0.262^{* *}$ \\
R-squared & $(0.028)$ & $(0.07)$ & $(0.102)$ \\
\hline \hline
\end{tabular}

Notes [1] In columns $1 \& 2$, controls include gender, a quadratic in age, education, income, religious denomination dummies and time and country fixed effects. Source: WVS; [2] In column 3, controls include gender, a quadratic in age, education, income, unemployment status, political orientation, religious denomination and country fixed effects. Source: ISSP. [3] In both specifications, standard errors are clustered at the country level, $* * *$ significant at $1 \%, * *$ significant at $5 \%, *$ significant at $10 \%$. 


\section{Appendix A}

The aim of this appendix is to analyze the model when assumption 1 is not fulfilled in order to provide necessary and sufficient conditions for the existence of every equilibrium.

Stage 3 is described in the main text. Let us describe stages 2 and 1.

Stage 2:

In stage 2, people vote to choose labor market institutions. The share of individuals with strong family ties, $\sigma$, chosen in stage 1 is given.

- First, let us analyze the situation where $\Delta(\sigma)>(1-c) / 2$. Then, if the labor market is rigid, workers with strong family ties are immobile, since $\Delta(\sigma)>1-c-\Delta(\sigma)$ and we can write their expected utility, defined equation (4) in the main text, in the simple following form:

$$
U_{R}^{S}=(1-R) w+\Delta(\sigma) .
$$

We can compute the maximum expected utility that an individual with strong family ties gets with a regulated labor market and compare it with what he gets when labor market are flexible to know when regulation is chosen rather than flexibility. The optimal labor market regulation is the couple of values of the minimum wage $w$ and of the reservation productivity $R$ that maximizes the expected utility of workers with strong family ties, defined by equation (1), subject to the zero profit condition:

$$
\int_{R}^{1}(y-c-w) \mathrm{d} y=0 .
$$

It is easily checked that the solution is

$$
R=c \text { and } w=\frac{1-c}{2}
$$

Then, in case of stringent labor market regulation, workers with strong family ties get the expected utility (from equations (1) and (3)):

$$
U_{R}^{S}=\frac{(1-c)^{2}}{2}+\Delta(\sigma)
$$

Comparison of this last equation and equation (2) in the main text implies that a median voter with strong family ties prefers a regulated labor market rather than a flexible labor market when $\Delta(\sigma)>(1-c) / 2$. If $\Delta(\sigma)>1 / 2, U_{F}^{S}=\Delta(\sigma)$ and it is obvious that $U_{R}^{S}>U_{F}^{S}$. If $(1-c)^{2} / 2<$ $\Delta(\sigma)<1 / 2, U_{F}^{S}=1-\Delta(\sigma)$ which is smaller than $U_{R}^{S}=\frac{(1-c)^{2}}{2}+\Delta(\sigma)$ if and only if $2 \Delta>1-\frac{(1-c)^{2}}{2}$, i.e. if the cost of labor market regulation is small enough with respect to the value of family ties.

- Now, let us analyze the situation where $\sigma>1 / 2$ and $\Delta(\sigma) \leq(1-c) / 2$. In this case, individuals with strong family ties move if they do not get a job in their birth place. The optimal labor regulation is the solution to

$$
\max _{(R, w)} U_{R}^{S}=(1-R)[w+\Delta(\sigma)]+R[1-c-\Delta(\sigma)]
$$

subject to

$$
\int_{R}^{1}(y-c-w) \mathrm{d} y=0
$$




$$
w+\Delta(\sigma) \geq 1-c-\Delta(\sigma)
$$

Let us denote by $\lambda$ and $\mu$ the Kuhn and Tucker multipliers associated with constraints (6) and (7) respectively. The first order conditions are

$$
\begin{array}{r}
1-c-w-2 \Delta(\sigma)-\lambda(R-c-w)=0 \\
(1-R)-\lambda(1-R)-\mu=0
\end{array}
$$

Suppose that constraint (7) is not binding so that $\mu=0$. From equation (9), $\mu=0$ implies that $\lambda=1$. Then, equations (6) and (8) imply that

$$
R=1-2 \Delta(\sigma) \text { and } w=1-c-\Delta(\sigma)
$$

Substituting this solution for $w$ into equation (7), it turns out that constraint (7) is never binding. Therefore, in the case where $\sigma>1 / 2$ and $\Delta(\sigma) \leq(1-c) / 2$, equations (5) and (10) imply that the expected utility obtained by individuals with strong family ties if the labor market is regulated is

$$
U_{R}^{S}=1-c-\Delta(\sigma)[1-2 \Delta(\sigma)]
$$

whereas individuals with strong family ties get

$$
U_{F}^{S}=1-\Delta(\sigma)
$$

if the labor market is flexible. Individuals with strong family ties prefer labor market rigidity if and only if

$$
1-c-\Delta(\sigma)[1-2 \Delta(\sigma)]>1-\Delta(\sigma)
$$

which is equivalent to

$$
c<2[\Delta(\sigma)]^{2} .
$$

Finally, the situation which arises in stage 2, where individuals vote to choose the type of labor market institution, can be summarized as follows:

- if $\sigma \leq 1 / 2$, the median voter, who has weak family ties, chooses labor market flexibility.

- if $\sigma>1 / 2$, the median voter, who has strong family ties, chooses to regulate the labor market if either $\Delta(1 / 2)>(1-c) / 2$ and $\Delta(1 / 2)<\frac{1}{2}-\frac{(1-c)^{2}}{4}$, or $\Delta(1 / 2) \leq(1-c) / 2$ and $c<2[\Delta(1 / 2)]^{2}$. Otherwise, the median voter chooses labor market flexibility. Figure A1 depicts the choice of voters when $\sigma \geq 1 / 2$ in the $(c, \Delta(1 / 2))$ plane. It turns out that labor market rigidity is chosen if the value of family ties is high with respect to the cost of labor market regulation.

Let us denote by $F$ the set of values of $\sigma$ such that flexibility is chosen in stage 2 .

Stage 1

In stage one, individuals choose their family values. They have perfect foresights. If they anticipate that $\sigma$, the share of individuals with strong family ties, belongs to $F$, they anticipate that labor market flexibility will be the outcome of the vote in stage 2. Otherwise, the outcome of the vote will be labor market regulation. Therefore, the expected utility of individuals with strong family ties is

$$
\begin{cases}\max [\Delta(\sigma), 1-\Delta(\sigma)] & \text { if } \sigma \in F \\ \Delta(\sigma)+\frac{(1-c)^{2}}{2} & \text { if } \sigma \notin F \text { and } \Delta(\sigma)>\frac{1-c}{2} \\ 1-c-\Delta(\sigma)[1-2 \Delta(\sigma)] & \text { if } \sigma \notin F \text { and } \Delta(\sigma) \leq \frac{1-c}{2}\end{cases}
$$


and the expected utility of individuals with weak family ties is ${ }^{1}$

$$
\begin{cases}1 & \text { if } \sigma \in F \\ 1-c & \text { if } \sigma \notin F\end{cases}
$$

Thus, the utility gains of choosing strong family ties rather than weak family ties are

$$
\Gamma(\sigma)= \begin{cases}\max [\Delta(\sigma), 1-\Delta(\sigma)]-1 & \text { if } \sigma \in F \\ \Delta(\sigma)-\frac{1-c^{2}}{2} & \text { if } \sigma \notin F \text { and } \Delta(\sigma)>\frac{1-c}{2} \\ \Delta(\sigma)[2 \Delta(\sigma)-1] & \text { if } \sigma \notin F \text { and } \Delta(\sigma) \leq \frac{1-c}{2}\end{cases}
$$

In a Nash equilibrium, every individual takes $\sigma$ as given and chooses strong family ties if the gains of doing so are positive and weak family ties otherwise.

It turns out that there exists a stable Nash equilibrium with $\sigma=0$ only if assumption 2 is satisfied, i.e. if $\Delta(0)<1$. If assumption 2 is not fulfilled, it is easily checked that $\Gamma(\sigma)>0$ for all $\sigma$, which implies that there is a single equilibrium with $\sigma=1$.

If assumption 2 is fulfilled, there is a stable equilibrium with $\sigma=0$. Then the definition of $\Gamma(\sigma)$ implies that there is either no other stable equilibrium if $\Delta(1) \leq \frac{1-c^{2}}{2}$ or another stable equilibrium with $\sigma=1$ if $\Delta(1)>\frac{1-c^{2}}{2}$.

\footnotetext{
${ }^{1}$ When the labor market is flexible, the minimum wage, $w=(1-c) / 2$, obtained by immobile workers, is smaller than $1-c$, the wage of mobile workers.
} 


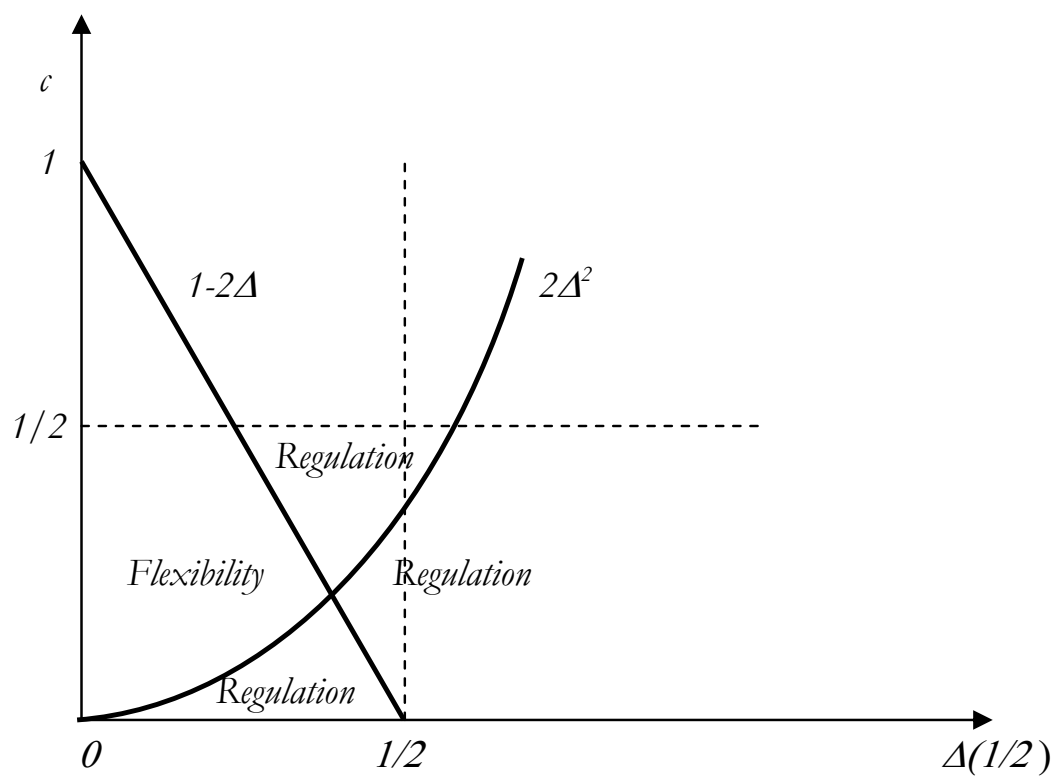

Figure A1: The choice of labor market regulation in stage 2 in the $(\Delta(1 / 2), c)$ plane when the share of individuals with strong family ties, $\sigma$, is larger than $1 / 2$. 


\section{APPENDIX B}

Table B1

Descriptive Statistics

\section{Panel A. World Value Survey and ISSP}

\begin{tabular}{lcccc}
\hline & \multicolumn{2}{c}{ WVS } & 1981-2005 & \multicolumn{2}{c}{ ISSP $(2006)$} \\
VARIABLES & Mean & Std & Mean & Std \\
\hline Age & 45.66 & 17.07 & 48.69 & 16.08 \\
Education & 14.85 & 5.29 & 12.20 & 4.42 \\
Male & .50 & .50 & .49 & .50 \\
Low income & .25 & .42 & .24 & .42 \\
Mid income & .50 & .49 & .49 & .49 \\
High Income & .25 & .43 & .27 & .44 \\
Employed & .53 & .49 & .63 & .48 \\
Unemployed & .05 & .21 & .04 & .19 \\
Inactive & .42 & .49 & .33 & .47 \\
Catholic & .60 & .48 & .51 & .49 \\
Protestant & .38 & .48 & .31 & .46 \\
Orthodox & .01 & .04 & .00 & .05 \\
Muslim & .01 & .04 & .01 & .08 \\
Buddhist & .00 & .04 & .00 & .02 \\
No religion & & & .17 & .38 \\
Left & .28 & .44 & .34 & .48 \\
Center & .44 & .49 & .38 & .48 \\
Right & .28 & .44 & .28 & .43 \\
Nuclear Family & .13 & .33 & .18 & .39 \\
Egalitarian & .27 & .44 & .20 & .38 \\
Stem & .43 & .49 & .50 & .50 \\
Incomplete Stem & .05 & .22 & .06 & .25 \\
Communitarian & .12 & .31 & .06 & .21 \\
\hline \hline
\end{tabular}

Panel B. Cross country regressions

\begin{tabular}{lcc}
\hline \hline & Mean & Std \\
\hline Firing costs & 0.479 & 0.371 \\
Demand for job security & 0.678 & 0.150 \\
Min. wage regulation & 0.028 & 0.073 \\
Demand for wage security & 0.594 & 0.175 \\
Share Living in parent. home & .259 & .104 \\
Legal origin: French & .475 & .504 \\
Legal origin: German & .237 & .429 \\
Legal origin: Scandinavian & .085 & .281 \\
\hline \hline
\end{tabular}


Panel C. General Social Survey and Current Population Survey

\begin{tabular}{lcccc}
\hline \hline & \multicolumn{2}{c}{ GSS $1977-$} & \multicolumn{2}{c}{ CPS 1994- } \\
& Mean & Std & Mean & Std \\
\hline Age & 44.38 & 17.14 & 33.75 & 12.36 \\
Female & 0.54 & 0.50 & 0.48 & 0.50 \\
Years of education & 12.57 & 3.08 & & \\
$<=12$ years of schooling & & & 0.45 & 0.50 \\
Some college & & & 0.23 & 0.42 \\
Income & 9.43 & 2.96 & 57205 & 49040 \\
Married & 0.59 & 0.49 & 0.46 & 0.50 \\
Single & 0.18 & 0.38 & 0.43 & 0.50 \\
Children & 1.99 & 1.83 & 0.83 & 1.14 \\
Unemployed & 0.03 & 0.17 & 0.08 & 0.28 \\
Employed & 0.62 & 0.48 & & \\
Inactive & 0.35 & & & \\
Mobility & & & 0.04 & 0.20 \\
Logwage & & & 2.28 & 0.76 \\
Experience & & & 14.09 & 12.12 \\
Job security & 2.39 & 1.21 & & \\
Save jobs & 3.49 & 1.10 & & \\
Set wages & 2.62 & 1.17 & & \\
Living with parents & 0.17 & 0.12 & 0.31 & 0.11 \\
Obedience & 0.37 & 0.16 & 0.44 & 0.14 \\
Make parents proud & 3.01 & 0.44 & 3.22 & 0.29 \\
Family important & 3.86 & 0.09 & 3.91 & 0.08 \\
\hline \hline
\end{tabular}


Table B2

Family Ties and the Regulation of Labor, Cross Country Evidence

\begin{tabular}{lcccc}
\hline \hline \multirow{2}{*}{ VARIABLES } & $\begin{array}{c}(1) \\
\text { Firing } \\
\text { Costs }\end{array}$ & $\begin{array}{c}(2) \\
\text { Demand for } \\
\text { job security }\end{array}$ & $\begin{array}{c}\text { Min. Wage } \\
\text { Regulation }\end{array}$ & $\begin{array}{c}(4) \\
\text { Demand for } \\
\text { wage security }\end{array}$ \\
\hline \multirow{3}{*}{ Share adult pop. in parent. home } & $1.003^{* * *}$ & $0.561^{* * *}$ & $0.047^{* *}$ & 0.763 \\
& $(0.320)$ & $(0.208)$ & $(0.019)$ & $(0.491)$ \\
LO: French & $0.353^{* * *}$ & $-0.066^{*}$ & -0.005 & $0.214^{* *}$ \\
& $(0.111)$ & $(0.036)$ & $(0.008)$ & $(0.089)$ \\
LO : German & $0.181^{*}$ & $-0.080^{*}$ & $-0.014^{*}$ & 0.138 \\
& $(0.104)$ & $(0.042)$ & $(0.008)$ & $(0.089)$ \\
LO : Scandinavian & $0.261^{* *}$ & -0.051 & $-0.032^{* * *}$ & -0.028 \\
& $(0.124)$ & $(0.063)$ & $(0.009)$ & $(0.137)$ \\
(Ln) Population & $0.085^{* * *}$ & 0.007 & -0.001 & -0.033 \\
& $(0.031)$ & $(0.012)$ & $(0.002)$ & $(0.031)$ \\
Observations & 60 & & & \\
R-squared & 0.389 & 0.250 & 0.384 & 0.560 \\
\hline \hline
\end{tabular}

LO : Common Law reference. Source: ISSP ILO, WB and WVS; Robust standard errors in parentheses, ${ }^{* *}$ significant at $1 \%,{ }^{* *}$ significant at $5 \%$, significant at $10 \%$.

Table B2 (bis)

Family ties and Employment Protection: Regular versus Temporary contracts, OECD countries

\begin{tabular}{lccc}
\hline \hline VARIABLES & $\begin{array}{c}(1) \\
\text { Regular } \\
\text { contracts }\end{array}$ & $\begin{array}{c}(2) \\
\text { Temporary } \\
\text { contracts }\end{array}$ & $\begin{array}{c}(3) \\
\text { Global } \\
\text { Index }\end{array}$ \\
\hline \multirow{2}{*}{ Family Ties } & $2.332^{*}$ & $2.680^{*}$ & $1.666^{*}$ \\
& $(1.215)$ & $(1.451)$ & $(0.824)$ \\
LO: French & $0.697^{*}$ & $2.342^{* * *}$ & $1.335^{* * *}$ \\
& $(0.341)$ & $(0.407)$ & $(0.231)$ \\
LO : German & $0.779 * *$ & $1.227^{* * *}$ & $0.937^{* * *}$ \\
& $(0.346)$ & $(0.413)$ & $(0.235)$ \\
LO : Scandinavian & $0.798^{*}$ & $1.314^{* *}$ & $0.929 * * *$ \\
& $(0.444)$ & $(0.530)$ & $(0.301)$ \\
(Ln) Population & -0.004 & 0.019 & -0.013 \\
& $(0.075)$ & $(0.089)$ & $(0.051)$
\end{tabular}

\begin{tabular}{lccc} 
Observations & 33 & 33 & 33 \\
R-squared & 0.287 & 0.631 & 0.625 \\
\hline
\end{tabular}

LO : Common Law reference. Source: WVS 1980-2000 and OECD 2008. Robust standard errors in parentheses, *** significant at $1 \%$, ** significant at $5 \%$, significant at $10 \%$. 
Table B3

Family Ties and Log Hourly Wages

Second gen. immigrants, CPS 1994-2012, controlling for real per capita GDP in the country of origin

\begin{tabular}{|c|c|c|c|c|c|c|}
\hline & $\begin{array}{c}(1) \\
\text { Log wage }\end{array}$ & $\begin{array}{c}(2) \\
\text { Log wage } \\
\end{array}$ & $\begin{array}{c}\text { (3) } \\
\text { Log wage } \\
\end{array}$ & $\begin{array}{c}\text { (4) } \\
\text { Log wage } \\
\end{array}$ & $\begin{array}{c}(5) \\
\text { Log wage } \\
\end{array}$ & $\begin{array}{c}\text { (6) } \\
\text { Log wage } \\
\end{array}$ \\
\hline Share of adult pop. in parent. home & $\begin{array}{c}-0.208^{* *} \\
(0.101)\end{array}$ & & & & & \\
\hline Respect parents & & $\begin{array}{l}-0.031 \\
(0.068)\end{array}$ & & & & \\
\hline Obedience & & & $\begin{array}{c}-0.179 * * \\
(0.080)\end{array}$ & & & \\
\hline Parents proud & & & & $\begin{array}{c}-0.073 * * \\
(0.035)\end{array}$ & & \\
\hline Parents responsibility & & & & & $\begin{array}{c}-0.093^{*} \\
(0.054)\end{array}$ & \\
\hline Family important & & & & & & $\begin{array}{c}-0.214 * * * \\
(0.079)\end{array}$ \\
\hline Real per capita GDP country of origin & $\begin{array}{l}-0.000 \\
(0.000)\end{array}$ & $\begin{array}{c}0.000^{* *} \\
(0.000)\end{array}$ & $\begin{array}{l}-0.000 \\
(0.000)\end{array}$ & $\begin{array}{c}0.000 \\
(0.000)\end{array}$ & $\begin{array}{l}0.000^{*} \\
(0.000)\end{array}$ & $\begin{array}{c}0.000^{* *} \\
(0.000)\end{array}$ \\
\hline Observations & 51902 & 57986 & 53024 & 52870 & 58034 & 58161 \\
\hline R-squared & 0.27 & 0.28 & 0.27 & 0.27 & 0.28 & 0.28 \\
\hline
\end{tabular}

Table B4

Family Ties and Mobility

Second Gen. Immigrants, CPS 1994-2012, controlling for real per capita GDP in the country of origin

\begin{tabular}{|c|c|c|c|c|c|c|}
\hline & $\begin{array}{c}(1) \\
\text { Mobility }\end{array}$ & $\begin{array}{c}(2) \\
\text { Mobility }\end{array}$ & $\begin{array}{c}\text { (3) } \\
\text { Mobility }\end{array}$ & $\begin{array}{c}\text { (4) } \\
\text { Mobility }\end{array}$ & $\begin{array}{c}(5) \\
\text { Mobility }\end{array}$ & $\begin{array}{c}\text { (6) } \\
\text { Mobility }\end{array}$ \\
\hline Share adult pop. in parent. home & $\begin{array}{c}-0.095^{* * *} \\
(0.030)\end{array}$ & & & & & \\
\hline Respect parents & & $\begin{array}{l}-0.040 \\
(0.033)\end{array}$ & & & & \\
\hline Obedience & & & $\begin{array}{c}-0.053^{* * *} \\
(0.017)\end{array}$ & & & \\
\hline Parents proud & & & & $\begin{array}{c}-0.024 * * \\
(0.010)\end{array}$ & & \\
\hline Parents responsibility & & & & & $\begin{array}{l}-0.028 \\
(0.021)\end{array}$ & \\
\hline Family important & & & & & & $\begin{array}{c}-0.055^{* * *} \\
(0.018)\end{array}$ \\
\hline Real per capita GDP country of origin & $\begin{array}{c}0.000 \\
(0.000)\end{array}$ & $\begin{array}{c}0.000^{* * *} \\
(0.000)\end{array}$ & $\begin{array}{c}0.000 * * \\
(0.000)\end{array}$ & $\begin{array}{c}0.000 \\
(0.000)\end{array}$ & $\begin{array}{c}0.000 * * * \\
(0.000)\end{array}$ & $\begin{array}{c}0.000^{* * *} \\
(0.000)\end{array}$ \\
\hline Observations & 72365 & 79093 & 73799 & 73510 & 79062 & 79243 \\
\hline
\end{tabular}

Robust standard errors are clustered at the country of origin level. *** significant at 1\%, ** significant at 5\%, * significant at $10 \%$. Mobility is defined as a dummy equal to 1 is the individual moved from/in a different state, or abroad in the last five years. Regressions control for a quadratic in age, education, marital status, gender, children, a dummy if the person is unemployed, real personal income, dummies for race, state and year fixed effects. Family ties variables are measured in the country of origin from the WVS. 
Table B5

Family Ties and Unemployment

Second Gen. Immigrants, CPS 1994-2012, controlling for real per capita GDP in the country of origin

\begin{tabular}{|c|c|c|c|c|c|c|}
\hline & $\begin{array}{c}(1) \\
\text { Unempl. }\end{array}$ & $\begin{array}{c}(2) \\
\text { Unempl. }\end{array}$ & $\begin{array}{c}\text { (3) } \\
\text { Unempl. }\end{array}$ & $\begin{array}{c}\text { (4) } \\
\text { Unempl. }\end{array}$ & $\begin{array}{c}\text { (5) } \\
\text { Unempl. }\end{array}$ & $\begin{array}{c}(6) \\
\text { Unempl. }\end{array}$ \\
\hline Share adult pop. in parent. home & $\begin{array}{c}0.066^{* * *} \\
(0.021)\end{array}$ & & & & & \\
\hline Respect parents & & $\begin{array}{c}0.026 \\
(0.018)\end{array}$ & & & & \\
\hline Obedience & & & $\begin{array}{c}0.044 * * * \\
(0.016)\end{array}$ & & & \\
\hline Make parents proud & & & & $\begin{array}{c}0.025^{* * *} \\
(0.009)\end{array}$ & & \\
\hline Parents responsbility & & & & & $\begin{array}{c}0.033^{* *} \\
(0.014)\end{array}$ & \\
\hline Family important & & & & & & $\begin{array}{c}0.052^{* * *} \\
(0.014)\end{array}$ \\
\hline Real per capita GDP country of origin & $\begin{array}{c}0.000 \\
(0.000)\end{array}$ & $\begin{array}{l}-0.000 \\
(0.000)\end{array}$ & $\begin{array}{l}-0.000 \\
(0.000)\end{array}$ & $\begin{array}{c}0.000 \\
(0.000)\end{array}$ & $\begin{array}{l}-0.000 \\
(0.000)\end{array}$ & $\begin{array}{c}-0.000 * * \\
(0.000)\end{array}$ \\
\hline Observations & 44220 & 48772 & 45180 & 45017 & 48765 & 48865 \\
\hline
\end{tabular}

Robust standard errors are clustered at the country of origin level. *** significant at $1 \%$, ** significant at $5 \%, *$ significant at $10 \%$. Unemployed is a dummy equal to 1 if the person is unemployed. Regressions control for a quadratic in age, education, marital status, a gender dummy, race dummies, state and year fixed effects. Family ties variables are measured in the country of origin from the WVS.

Table B6

Family Values and Demand for Labor Regulation, controlling for real per capita GDP in the country of origin, Average Effect Size Coefficients - GSS 1977-2010

\begin{tabular}{|c|c|c|c|c|c|c|}
\hline & $\begin{array}{c}(1) \\
\text { AES }\end{array}$ & $\begin{array}{c}(2) \\
\text { AES }\end{array}$ & $\begin{array}{c}(3) \\
\text { AES }\end{array}$ & $\begin{array}{c}(4) \\
\text { AES }\end{array}$ & $\begin{array}{c}(5) \\
\text { AES }\end{array}$ & $\begin{array}{c}(6) \\
\text { AES }\end{array}$ \\
\hline Share adult pop. in parent. home & $\begin{array}{c}0.506^{* * *} \\
(0.163)\end{array}$ & & & & & \\
\hline Respect parents & & $\begin{array}{c}0.296^{* *} \\
(0.125)\end{array}$ & & & & \\
\hline Obedience & & & $\begin{array}{c}0.037 \\
(0.084)\end{array}$ & & & \\
\hline Parents proud & & & & $\begin{array}{c}0.056 \\
(0.070)\end{array}$ & 0.137 & \\
\hline Parents responsibility & & & & & $(0.100)$ & \\
\hline Family important & & & & & & $(0.124)$ \\
\hline Real per capita GDP country origin & $\begin{array}{l}-0.000 \\
(0.000)\end{array}$ & $\begin{array}{l}-0.000 \\
(0.000)\end{array}$ & $\begin{array}{c}-0.000^{* *} \\
(0.000)\end{array}$ & $\begin{array}{l}-0.000 \\
(0.000)\end{array}$ & $\begin{array}{c}-0.000^{* *} \\
(0.000)\end{array}$ & $\begin{array}{c}-0.000^{* *} \\
(0.000)\end{array}$ \\
\hline Observations & 4059 & 4017 & 4059 & 3340 & 4050 & 4059 \\
\hline
\end{tabular}

Robust standard errors are clustered at the ancestry level. *** significant at 1\%, ** significant at 5\%, * significant at $10 \%$. AES averages the normalized treatment effects obtained from a seemingly unrelated regression in which each dependent variable is one of the desire for regulation measure. All regressions control for a quadratic in age, education, income, marital and employment status, number of children, gender dummies and region fixed effects. Family ties variables are measured in the country of origin from the WVS. The number of observations is the average number of observations in the regressions for the three attitude variables toward regulation. 
Table B7

Family Ties and Log Hourly Wages

Second Generation Immigrants, CPS 1994-2012

Controlling for human capital in the country of origin

\begin{tabular}{|c|c|c|c|c|c|c|}
\hline & $\begin{array}{c}(1) \\
\text { Log wage }\end{array}$ & $\begin{array}{c}(2) \\
\text { Log wage } \\
\end{array}$ & $\begin{array}{c}(3) \\
\text { Log wage } \\
\end{array}$ & $\begin{array}{c}\text { (4) } \\
\text { Log wage }\end{array}$ & $\begin{array}{c}(5) \\
\text { Log wage } \\
\end{array}$ & $\begin{array}{c}(6) \\
\text { Log wage }\end{array}$ \\
\hline Share adult pop. in parent. home & $\begin{array}{c}-0.254^{* *} \\
(0.109)\end{array}$ & & & & & \\
\hline Respect parents & & $\begin{array}{l}-0.099 \\
(0.060)\end{array}$ & & & & \\
\hline Obedience & & & $\begin{array}{l}-0.168^{*} \\
(0.084)\end{array}$ & & & \\
\hline Make parents proud & & & & $\begin{array}{c}-0.071 * * \\
(0.033)\end{array}$ & & \\
\hline Parents responsibility & & & & & $\begin{array}{c}-0.112 * * \\
(0.055)\end{array}$ & \\
\hline Family important & & & & & & $\begin{array}{c}-0.216^{* * *} \\
(0.072)\end{array}$ \\
\hline Human capital country of origin & $\begin{array}{l}-0.004 \\
(0.007)\end{array}$ & $\begin{array}{c}0.006 \\
(0.004)\end{array}$ & $\begin{array}{c}0.001 \\
(0.005)\end{array}$ & $\begin{array}{c}0.002 \\
(0.005)\end{array}$ & $\begin{array}{c}0.006 \\
(0.004)\end{array}$ & $\begin{array}{l}0.007^{*} \\
(0.004)\end{array}$ \\
\hline Observations & 51049 & 57133 & 52171 & 52017 & 57181 & 57308 \\
\hline R-squared & 0.27 & 0.27 & 0.27 & 0.27 & 0.27 & 0.28 \\
\hline \multicolumn{7}{|c|}{$\begin{array}{c}\text { Table B8 } \\
\text { Family Ties and Mobility } \\
\text { Second Gen. Immigrants, CPS 1994-2012, controlling for human capital in the country of origin }\end{array}$} \\
\hline & $\begin{array}{c}(1) \\
\text { Mobility }\end{array}$ & $\begin{array}{c}(2) \\
\text { Mobility }\end{array}$ & $\begin{array}{c}\text { (3) } \\
\text { Mobility }\end{array}$ & $\begin{array}{c}(4) \\
\text { Mobility }\end{array}$ & $\begin{array}{c}(5) \\
\text { Mobility }\end{array}$ & $\begin{array}{c}(6) \\
\text { Mobility }\end{array}$ \\
\hline Share adult pop. in parent. home & $\begin{array}{c}-0.058^{* *} \\
(0.027)\end{array}$ & & & & & \\
\hline Respect parents & & $\begin{array}{l}-0.043 * \\
(0.023)\end{array}$ & & & & \\
\hline Obedience & & & $\begin{array}{c}-0.042^{* *} \\
(0.017)\end{array}$ & & & \\
\hline Parents proud & & & & $\begin{array}{c}-0.019 * * * \\
(0.007)\end{array}$ & & \\
\hline Parents responsibility & & & & & $\begin{array}{l}-0.031 * \\
(0.016)\end{array}$ & \\
\hline Family important & & & & & & $\begin{array}{c}-0.054 * * * \\
(0.010)\end{array}$ \\
\hline Human capital in the country of origin & $\begin{array}{c}0.005^{* * *} \\
(0.002)\end{array}$ & $\begin{array}{c}0.006^{* * *} \\
(0.001)\end{array}$ & $\begin{array}{c}0.005^{* * *} \\
(0.001)\end{array}$ & $\begin{array}{c}0.005^{* * *} \\
(0.001)\end{array}$ & $\begin{array}{c}0.007 * * * \\
(0.001)\end{array}$ & $\begin{array}{c}0.007 * * * \\
(0.001)\end{array}$ \\
\hline Observations & 71215 & 77943 & 72649 & 72360 & 77912 & 78093 \\
\hline
\end{tabular}

Robust standard errors are clustered at the country of origin level. *** significant at $1 \%$, ** significant at $5 \%$, * significant at $10 \%$. Mobility is defined as a dummy equal to 1 is the individual moved from/in a different state, or abroad in the last five years. Regressions control for a quadratic in age, education, marital status, gender, children, a dummy if the person is unemployed, real personal income, dummies for race, state and year fixed effects. Family ties variables are measured in the country of origin from the WVS. 
Table B9

Family Ties and Unemployment

Second Gen. Immigrants, CPS 1994-2012, controlling for human capital in the country of origin

\begin{tabular}{|c|c|c|c|c|c|c|}
\hline & $\begin{array}{c}(1) \\
\text { Unempl. }\end{array}$ & $\begin{array}{c}(2) \\
\text { Unempl. }\end{array}$ & $\begin{array}{c}\text { (3) } \\
\text { Unempl. }\end{array}$ & $\begin{array}{c}\text { (4) } \\
\text { Unempl. }\end{array}$ & $\begin{array}{c}(5) \\
\text { Unempl. }\end{array}$ & $\begin{array}{c}(6) \\
\text { Unempl }\end{array}$ \\
\hline Share adult pop. in parent. home & $\begin{array}{c}0.064^{* * *} \\
(0.020)\end{array}$ & & & & & \\
\hline Respect parents & & $\begin{array}{c}0.030^{* *} \\
(0.013)\end{array}$ & & & & \\
\hline Obedience & & & $\begin{array}{c}0.041 * * \\
(0.017)\end{array}$ & & & \\
\hline Parents proud & & & & $\begin{array}{c}0.021 * * * \\
(0.008)\end{array}$ & & \\
\hline Parents responsibility & & & & & $\begin{array}{c}0.034 * * * \\
(0.012)\end{array}$ & \\
\hline Family important & & & & & & $\begin{array}{c}0.054^{* * *} \\
(0.013)\end{array}$ \\
\hline Human capital in the country of origin & $\begin{array}{c}0.000 \\
(0.001)\end{array}$ & $\begin{array}{c}-0.002 * \\
(0.001)\end{array}$ & $\begin{array}{l}-0.001 \\
(0.001)\end{array}$ & $\begin{array}{l}-0.001 \\
(0.001)\end{array}$ & $\begin{array}{l}-0.002 * \\
(0.001)\end{array}$ & $\begin{array}{c}-0.002 * * \\
(0.001)\end{array}$ \\
\hline Observations & 43506 & 48058 & 44466 & 44303 & 48051 & 48151 \\
\hline \multirow{2}{*}{\multicolumn{7}{|c|}{$\begin{array}{l}\text { Robust standard errors are clustered at the country of origin level. *** significant at } 1 \%, * * \text { significant at } 5 \% \text {, significant at } 10^{\circ} \\
\text { Unemployed is a dummy equal to } 1 \text { if the person is unemployed. Regressions control for a quadratic in age, education, mari } \\
\text { status, a gender dummy, race dummies, state and year fixed effects. Family ties variables are measured in the country of origin fro } \\
\text { the WVS. } \\
\text { Table B10 } \\
\text { Family Values and Demand for Labor Regulation, controlling human capital in the country of origin } \\
\text { (Average Effect Size Coefficients - GSS 1977-2010) }\end{array}$}} \\
\hline & & & & & & \\
\hline & $\begin{array}{c}\text { (1) } \\
\text { AES }\end{array}$ & $\begin{array}{c}(2) \\
\text { AES }\end{array}$ & $\begin{array}{c}\text { (3) } \\
\text { AES }\end{array}$ & $\begin{array}{c}\text { (4) } \\
\text { AES }\end{array}$ & $\begin{array}{c}\text { (5) } \\
\text { AES }\end{array}$ & $\begin{array}{c}(6) \\
\text { AES }\end{array}$ \\
\hline Share adult pop. in parent. home & $\begin{array}{l}0.335^{*} \\
(0.204)\end{array}$ & & & & & \\
\hline Respect parents & & $\begin{array}{c}0.222^{* *} \\
(0.106)\end{array}$ & & & & \\
\hline Obedience & & & $\begin{array}{l}-0.063 \\
(0.091)\end{array}$ & & & \\
\hline Parents proud & & & & $\begin{array}{c}0.040 \\
(0.067)\end{array}$ & & \\
\hline Parents responsibility & & & & & $\begin{array}{l}0.137 * \\
(0.081)\end{array}$ & \\
\hline Family important & & & & & & $\begin{array}{l}-0.090 \\
(0.116)\end{array}$ \\
\hline Human capital country of origin & $\begin{array}{c}-0.025^{* *} \\
(0.012)\end{array}$ & $\begin{array}{c}-0.032 * * * \\
(0.011)\end{array}$ & $\begin{array}{c}-0.045^{* * *} \\
(0.014)\end{array}$ & $\begin{array}{c}-0.038^{* * *} \\
(0.014)\end{array}$ & $\begin{array}{c}-0.048^{* * *} \\
(0.014)\end{array}$ & $\begin{array}{c}-0.044 * * * \\
(0.013)\end{array}$ \\
\hline Observations & 4059 & 4017 & 4059 & 3340 & 4050 & 4059 \\
\hline
\end{tabular}

Robust standard errors are clustered at the ancestry level. $* * *$ significant at $1 \%, * *$ significant at $5 \%, *$ significant at $10 \%$. AES averages the normalized treatment effects obtained from a seemingly unrelated regression in which each dependent variable is one of the desire for regulation measure. All regressions control for a quadratic in age, education, income, marital and employment status, number of children, gender dummies and region fixed effects. Family ties variables are measured in the country of origin from the WVS. The number of observations is the average number of observations in the regressions for the three attitude variables toward regulation. 
Table B11

Family Values and Demand for Labor Regulation, controlling for parents' education Average Effect Size Coefficients - GSS 1977-2010

\begin{tabular}{|c|c|c|c|c|c|c|}
\hline & $\begin{array}{c}(1) \\
\text { AES }\end{array}$ & $\begin{array}{c}(2) \\
\text { AES }\end{array}$ & $\begin{array}{c}(3) \\
\text { AES }\end{array}$ & $\begin{array}{c}(4) \\
\text { AES }\end{array}$ & $\begin{array}{c}(5) \\
\text { AES }\end{array}$ & $\begin{array}{c}(6) \\
\text { AES }\end{array}$ \\
\hline Share adult pop. in parent. home & $\begin{array}{c}0.436 * * * \\
(0.095)\end{array}$ & & & & & \\
\hline Respect parents & & $\begin{array}{c}0.347 * * * \\
(0.081)\end{array}$ & & & & \\
\hline Obedience & & & $\begin{array}{c}0.229^{* * *} \\
(0.084)\end{array}$ & & & \\
\hline Parents proud & & & & $\begin{array}{c}0.106^{* * *} \\
(0.029)\end{array}$ & & \\
\hline Parents responsibility & & & & & $\begin{array}{c}0.318^{* * * *} \\
(0.109)\end{array}$ & \\
\hline Family important & & & & & & $\begin{array}{c}0.340^{* * *} \\
(0.127)\end{array}$ \\
\hline Observations & 4123 & 4091 & 4123 & 3632 & 4116 & 4123 \\
\hline $\begin{array}{l}\text { Robust standard errors are clustered a } \\
\text { AES averages the normalized treatme } \\
\text { variable is one of the desire for regula } \\
\text { both parents, income, marital and er } \\
\text { Family ties variables are measured in } \\
\text { number of observations in the regressi }\end{array}$ & $\begin{array}{l}\text { he ancestry } \\
\text { effects obt } \\
\text { n measure. } \\
\text { loyment st } \\
\text { e country }\end{array}$ & $\begin{array}{l}\text { el. } * * * \text { sigr } \\
\text { ed from a } \\
\text { regressior } \\
\text {, number } \\
\text { rigin from }\end{array}$ & $\begin{array}{l}\text { ant at } 1 \% \text {, } \\
\text { ningly unre } \\
\text { ontrol for } \\
\text { children, g } \\
\text { e WVS. Th }\end{array}$ & $\begin{array}{l}\text { significant } \\
\text { ed regressio } \\
\text { ladratic in } \\
\text { er dummic } \\
\text { lumber of }\end{array}$ & $\begin{array}{l}\%,{ }^{*} \text { signi } \\
\mathrm{n} \text { which ea } \\
\text { education } \\
\text { and region } \\
\text { servations }\end{array}$ & $\begin{array}{l}\text { ant at } 10 \% \text {. } \\
\text { dependent } \\
\text { ducation of } \\
\text { xed effects. } \\
\text { the average }\end{array}$ \\
\hline
\end{tabular}

Table B12

Family Ties and Log Hourly Wages

Second Generation Immigrants, CPS 1994-2012

Controlling for ethnic human capital of first generation immigrants

\begin{tabular}{|c|c|c|c|c|c|c|}
\hline & $\begin{array}{c}(1) \\
\text { Log wage }\end{array}$ & $\begin{array}{c}(2) \\
\text { Log wage }\end{array}$ & $\begin{array}{c}(3) \\
\text { Log wage }\end{array}$ & $\begin{array}{c}\text { (4) } \\
\text { Log wage }\end{array}$ & $\begin{array}{c}(5) \\
\text { Log wage }\end{array}$ & $\begin{array}{c}(6) \\
\text { Log wage }\end{array}$ \\
\hline Share of adult pop. in parental home & $\begin{array}{l}-0.104^{*} \\
(0.061)\end{array}$ & & & & & \\
\hline Respect parents & & $\begin{array}{l}-0.062 \\
(0.056)\end{array}$ & & & & \\
\hline Obedience & & & $\begin{array}{c}-0.144 * * \\
(0.060)\end{array}$ & & & \\
\hline Parents proud & & & & $\begin{array}{c}-0.073 * * * \\
(0.026)\end{array}$ & & \\
\hline Parents responsibility & & & & & $\begin{array}{c}-0.115^{* *} \\
(0.044)\end{array}$ & \\
\hline Family important & & & & & & $\begin{array}{c}-0.179 * * * \\
(0.064)\end{array}$ \\
\hline Ethnic human capital & $\begin{array}{c}0.028^{* *} \\
(0.010)\end{array}$ & $\begin{array}{c}0.036^{* * *} \\
(0.007)\end{array}$ & $\begin{array}{c}0.031^{* * *} \\
(0.008)\end{array}$ & $\begin{array}{c}0.033^{* * *} \\
(0.006)\end{array}$ & $\begin{array}{c}0.039 * * * \\
(0.006)\end{array}$ & $\begin{array}{c}0.035^{* * *} \\
(0.007)\end{array}$ \\
\hline Observations & 51618 & 63991 & 52740 & 52586 & 64039 & 64166 \\
\hline R-squared & 0.28 & 0.28 & 0.28 & 0.28 & 0.28 & 0.28 \\
\hline
\end{tabular}


Table B13

Family Ties and Mobility

Second Generation Immigrants, CPS 1994-2012

Controlling for ethnic human capital of first generation immigrants

\begin{tabular}{|c|c|c|c|c|c|c|}
\hline & $\begin{array}{c}\text { (1) } \\
\text { Mobility }\end{array}$ & $\begin{array}{c}(2) \\
\text { Mobility }\end{array}$ & $\begin{array}{c}\text { (3) } \\
\text { Mobility }\end{array}$ & $\begin{array}{c}\text { (4) } \\
\text { Mobility }\end{array}$ & $\begin{array}{c}(5) \\
\text { Mobility }\end{array}$ & $\begin{array}{c}(6) \\
\text { Mobility }\end{array}$ \\
\hline Share adult pop. in parent. home & $\begin{array}{c}-0.118^{* * *} \\
(0.024)\end{array}$ & & & & & \\
\hline Respect parents & & $\begin{array}{c}-0.094 * * * \\
(0.028)\end{array}$ & & & & \\
\hline Obedience & & & $\begin{array}{c}-0.078^{* * *} \\
(0.015)\end{array}$ & & & \\
\hline Parents proud & & & & $\begin{array}{c}-0.037 * * * \\
(0.006)\end{array}$ & & \\
\hline Parents responsibility & & & & & $\begin{array}{c}-0.063^{* * *} \\
(0.018)\end{array}$ & \\
\hline Family important & & & & & & $\begin{array}{c}-0.079 * * * \\
(0.026)\end{array}$ \\
\hline Ethnic human capital & $\begin{array}{l}-0.001 \\
(0.004)\end{array}$ & $\begin{array}{c}0.005^{* *} \\
(0.002)\end{array}$ & $\begin{array}{l}0.004 * \\
(0.002)\end{array}$ & $\begin{array}{c}0.006^{* *} \\
(0.002)\end{array}$ & $\begin{array}{c}0.008^{* * *} \\
(0.003)\end{array}$ & $\begin{array}{c}0.006^{* *} \\
(0.003)\end{array}$ \\
\hline Observations & 72160 & 88649 & 73594 & 73305 & 88618 & 88799 \\
\hline
\end{tabular}

Robust standard errors are clustered at the country of origin level. *** significant at $1 \%$, ** significant at 5\%, * significant at $10 \%$. Mobility is defined as a dummy equal to 1 is the individual moved from/in a different state, or abroad in the last five years. Regressions control for a quadratic in age, education, marital status, gender, children, a dummy if the person is unemployed, real personal income, dummies for race, state and year fixed effects. Family ties variables are measured in the country of origin from the WVS.

\section{Table B14}

Family Ties and Unemployment

Second Gen. Immigrants, CPS 1994-2012

Controlling for ethnic human capital of first generation immigrants

\begin{tabular}{|c|c|c|c|c|c|c|}
\hline & $\begin{array}{c}1) \\
\text { Unempl. }\end{array}$ & $\begin{array}{c}(2) \\
\text { Unempl. }\end{array}$ & $\begin{array}{c}(3) \\
\text { Unempl. }\end{array}$ & $\begin{array}{c}(4) \\
\text { Unempl. }\end{array}$ & $\begin{array}{c}5) \\
\text { Unempl. }\end{array}$ & $\begin{array}{c}(6) \\
\text { Unempl. }\end{array}$ \\
\hline Share adult pop. in parent. home & $\begin{array}{c}0.051^{* * *} \\
(0.015)\end{array}$ & & & & & \\
\hline Respect parents & & $\begin{array}{c}0.043 * * * \\
(0.012)\end{array}$ & & & & \\
\hline Obedience & & & $\begin{array}{c}0.046^{* * *} \\
(0.010)\end{array}$ & & & \\
\hline Make parents proud & & & & $\begin{array}{c}0.023 * * * \\
(0.005)\end{array}$ & & \\
\hline Parents responsibility & & & & & $\begin{array}{c}0.044 * * * \\
(0.011)\end{array}$ & \\
\hline Family important & & & & & & $\begin{array}{c}0.061^{* * *} \\
(0.010)\end{array}$ \\
\hline Ethnic human capital & $\begin{array}{l}-0.003 \\
(0.002)\end{array}$ & $\begin{array}{c}-0.004 * * * \\
(0.001)\end{array}$ & $\begin{array}{c}-0.005^{* * *} \\
(0.001)\end{array}$ & $\begin{array}{c}-0.006 \text { *** } \\
(0.001)\end{array}$ & $\begin{array}{c}-0.005^{* * *} \\
(0.001)\end{array}$ & $\begin{array}{c}-0.004^{* * *} \\
(0.002)\end{array}$ \\
\hline $\begin{array}{l}\text { Number of countries } \\
\text { Observations }\end{array}$ & 44123 & 54678 & 45083 & 44920 & 54671 & 54771 \\
\hline
\end{tabular}


Table B15

Family Values and Demand for Labor Regulation, controlling for ethnic human capital of first generation immigrants, Average Effect Size Coefficients - GSS 1977-2010

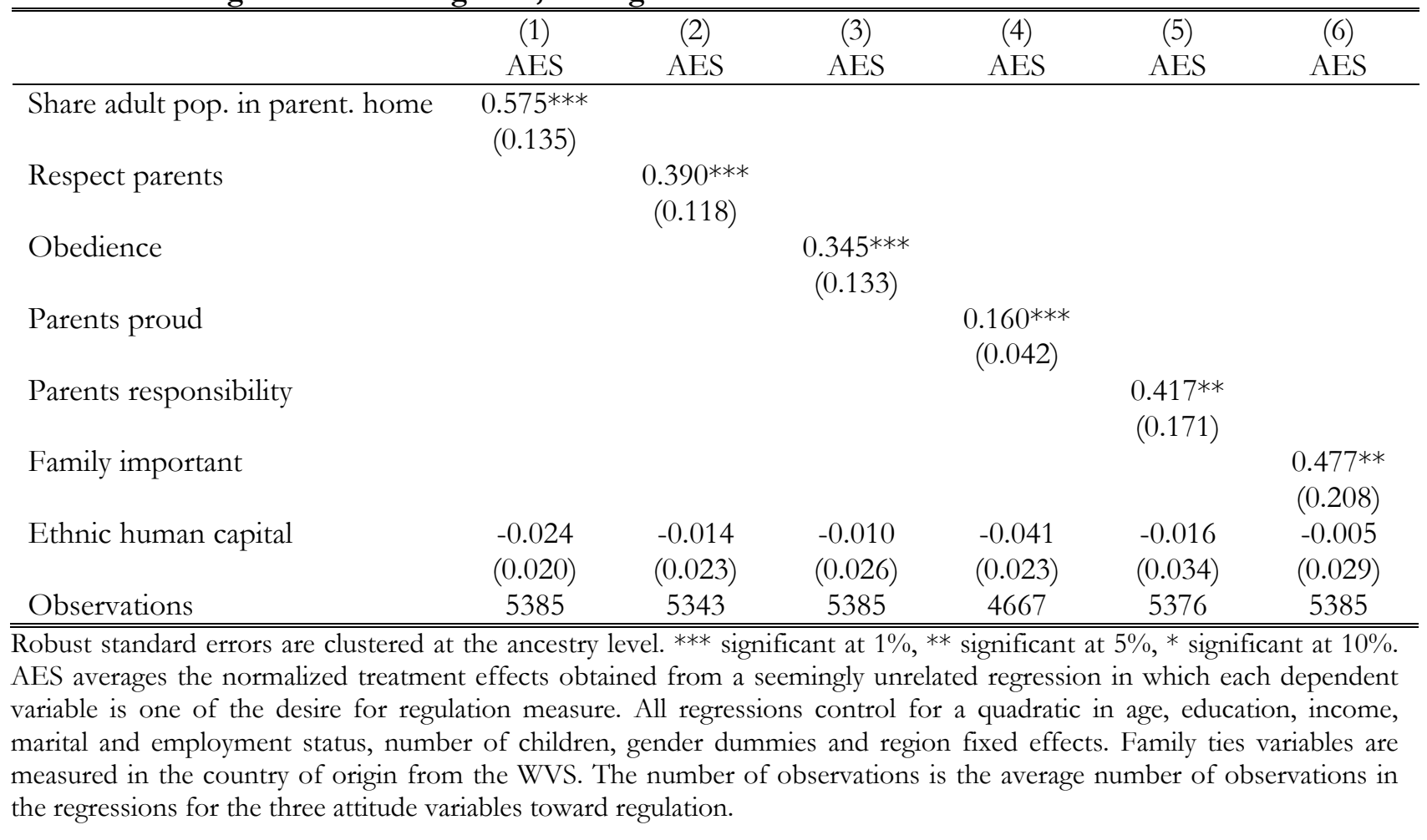

Table B16

Family Ties and Log Hourly Wages Second Generation Immigrants, CPS 1994-2012, controlling for trust as a cultural variable

\begin{tabular}{|c|c|c|c|c|c|c|}
\hline & $\begin{array}{c}(1) \\
\text { Log wage }\end{array}$ & $\begin{array}{c}(2) \\
\text { Log wage }\end{array}$ & $\begin{array}{c}(3) \\
\text { Log wage }\end{array}$ & $\begin{array}{c}(4) \\
\text { Log wage }\end{array}$ & $\begin{array}{c}(5) \\
\text { Log wage }\end{array}$ & $\begin{array}{c}(6) \\
\text { Log wage }\end{array}$ \\
\hline Share adult pop. in parent. home & $\begin{array}{l}-0.114 \\
(0.072)\end{array}$ & & & & & \\
\hline Respect parents & & $\begin{array}{l}-0.123 \\
(0.080)\end{array}$ & & & & \\
\hline Obedience & & & $\begin{array}{c}-0.164^{* *} \\
(0.072)\end{array}$ & & & \\
\hline Make parents proud & & & & $\begin{array}{c}-0.073^{* * *} \\
(0.025)\end{array}$ & & \\
\hline Parents responsibility & & & & & $\begin{array}{l}-0.097 * \\
(0.051)\end{array}$ & \\
\hline Family important & & & & & & $\begin{array}{c}-0.243^{* *} \\
(0.096)\end{array}$ \\
\hline Trust & $\begin{array}{l}0.133^{*} \\
(0.078)\end{array}$ & $\begin{array}{c}0.100 \\
(0.076)\end{array}$ & $\begin{array}{c}0.061 \\
(0.072)\end{array}$ & $\begin{array}{c}0.040 \\
(0.077)\end{array}$ & $\begin{array}{c}0.101 \\
(0.066)\end{array}$ & $\begin{array}{c}0.067 \\
(0.065)\end{array}$ \\
\hline Observations & 60962 & 77983 & 62291 & 62137 & 78031 & 78158 \\
\hline R-squared & 0.27 & 0.27 & 0.27 & 0.27 & 0.27 & 0.27 \\
\hline
\end{tabular}


Table B17

Family Ties and Mobility

Second Generation Immigrants, CPS 1994-2012, controlling for trust as a cultural variable

\begin{tabular}{|c|c|c|c|c|c|c|}
\hline & $\begin{array}{c}\text { (1) } \\
\text { Mobility }\end{array}$ & $\begin{array}{c}(2) \\
\text { Mobility } \\
\end{array}$ & $\begin{array}{c}\text { (3) } \\
\text { Mobility }\end{array}$ & $\begin{array}{c}\text { (4) } \\
\text { Mobility }\end{array}$ & $\begin{array}{c}(5) \\
\text { Mobility }\end{array}$ & $\begin{array}{c}(6) \\
\text { Mobility }\end{array}$ \\
\hline Share adult pop. in parent. home & $\begin{array}{c}-0.108^{* * *} \\
(0.015)\end{array}$ & & & & & \\
\hline Respect parents & & $\begin{array}{c}-0.072^{* * *} \\
(0.024)\end{array}$ & & & & \\
\hline Obedience & & & $\begin{array}{c}-0.061 * * * \\
(0.015)\end{array}$ & & & \\
\hline Parents proud & & & & $\begin{array}{c}-0.025^{* * *} \\
(0.009)\end{array}$ & & \\
\hline Parents responsibility & & & & & $\begin{array}{l}-0.028 \\
(0.020)\end{array}$ & \\
\hline Family important & & & & & & $\begin{array}{l}-0.055 \\
(0.035)\end{array}$ \\
\hline Trust & $\begin{array}{l}0.030^{*} \\
(0.017)\end{array}$ & $\begin{array}{c}0.017 \\
(0.022)\end{array}$ & $\begin{array}{c}0.019 \\
(0.020)\end{array}$ & $\begin{array}{c}0.017 \\
(0.026)\end{array}$ & $\begin{array}{c}0.038 \\
(0.026)\end{array}$ & $\begin{array}{c}0.033 \\
(0.028)\end{array}$ \\
\hline Observations & 86482 & 109871 & 88176 & 87887 & 109840 & 110021 \\
\hline
\end{tabular}

Robust standard errors are clustered at the country of origin level. ${ }^{* * *}$ significant at $1 \%$, $* *$ significant at $5 \%,{ }^{*}$ significant at $10 \%$. Mobility is defined as a dummy equal to 1 is the individual moved from/in a different state, or abroad in the last five years. Regressions control for a quadratic in age, education, marital status, gender, children, a dummy if the person is unemployed, real personal income, dummies for race, state and year fixed effects. Family ties variables are measured in the country of origin from the WVS.

\section{Table B18}

Family Ties and Unemployment Second Generation Immigrants, CPS 1994-2012, controlling for trust as a cultural variable

\begin{tabular}{|c|c|c|c|c|c|c|}
\hline & $\begin{array}{c}\text { (1) } \\
\text { Unempl. }\end{array}$ & $\begin{array}{c}(2) \\
\text { Unempl. }\end{array}$ & $\begin{array}{c}\text { (3) } \\
\text { Unempl. }\end{array}$ & $\begin{array}{c}\text { (4) } \\
\text { Unempl. }\end{array}$ & $\begin{array}{c}\text { (5) } \\
\text { Unempl. }\end{array}$ & $\begin{array}{c}\text { (6) } \\
\text { Unempl. }\end{array}$ \\
\hline Share adult pop. in parent. home & $\begin{array}{c}0.026 \\
(0.018)\end{array}$ & & & & & \\
\hline Respect parents & & $\begin{array}{c}0.053^{* * *} \\
(0.019)\end{array}$ & & & & \\
\hline Obedience & & & $\begin{array}{c}0.050^{* * *} \\
(0.014)\end{array}$ & & & \\
\hline Parents proud & & & & $\begin{array}{c}0.024 * * * \\
(0.006)\end{array}$ & & \\
\hline Parents responsibility & & & & & $\begin{array}{c}0.049 * * * \\
(0.013)\end{array}$ & \\
\hline Family important & & & & & & $\begin{array}{c}0.080^{* * *} \\
(0.021)\end{array}$ \\
\hline Trust & $\begin{array}{c}-0.039 * * \\
(0.017)\end{array}$ & $\begin{array}{l}-0.020 \\
(0.022)\end{array}$ & $\begin{array}{l}-0.012 \\
(0.016)\end{array}$ & $\begin{array}{l}-0.005 \\
(0.018)\end{array}$ & $\begin{array}{l}-0.006 \\
(0.018)\end{array}$ & $\begin{array}{l}-0.009 \\
(0.017)\end{array}$ \\
\hline Observations & 52982 & 67665 & 54117 & 53954 & 67658 & 67758 \\
\hline
\end{tabular}


Table B19

Family Values and Demand for Labor Regulation, controlling for trust as a cultural variable Average Effect Size Coefficients - GSS 1977-2010

\begin{tabular}{|c|c|c|c|c|c|c|}
\hline & $\begin{array}{c}(1) \\
\text { AES }\end{array}$ & $\begin{array}{c}(2) \\
\text { AES }\end{array}$ & $\begin{array}{c}(3) \\
\text { AES }\end{array}$ & $\begin{array}{c}(4) \\
\text { AES }\end{array}$ & $\begin{array}{c}(5) \\
\text { AES }\end{array}$ & $\begin{array}{c}(6) \\
\text { AES }\end{array}$ \\
\hline Share adult pop. in parent. home & $\begin{array}{c}0.496^{* * *} \\
(0.102)\end{array}$ & & & & & \\
\hline Respect parents & & $\begin{array}{c}0.397 * * * \\
(0.086)\end{array}$ & & & & \\
\hline Obedience & & & $\begin{array}{c}0.235^{* * *} \\
(0.088)\end{array}$ & & & \\
\hline Parents proud & & & & $\begin{array}{c}0.127 * * * \\
(0.033)\end{array}$ & & \\
\hline Parents responsibility & & & & & $\begin{array}{c}0.363^{* * *} \\
(0.101)\end{array}$ & \\
\hline Family important & & & & & & $\begin{array}{c}0.426 * * \\
(0.177)\end{array}$ \\
\hline Trust & $\begin{array}{c}0.087 * * * \\
(0.021)\end{array}$ & $\begin{array}{c}0.084^{* * *} \\
(0.020)\end{array}$ & $\begin{array}{c}0.095^{* * *} \\
(0.020)\end{array}$ & $\begin{array}{c}0.075^{* * *} \\
(0.019)\end{array}$ & $\begin{array}{c}0.092^{* * *} \\
(0.021)\end{array}$ & $\begin{array}{c}0.095^{* * *} \\
(0.020)\end{array}$ \\
\hline Observations & 3853 & 3827 & 3853 & 3417 & 3848 & 3853 \\
\hline
\end{tabular}


Table B20

Family Ties and Mobility

Second Generation Immigrants, Census 1940, 1960 and 1970

CENSUS 1940

\begin{tabular}{|c|c|c|c|c|c|c|}
\hline & $\begin{array}{c}(1) \\
\text { Mobility }\end{array}$ & $\begin{array}{c}(2) \\
\text { Mobility }\end{array}$ & $\begin{array}{c}\text { (3) } \\
\text { Mobility }\end{array}$ & $\begin{array}{c}(4) \\
\text { Mobility }\end{array}$ & $\begin{array}{c}(5) \\
\text { Mobility }\end{array}$ & $\begin{array}{c}\text { (6) } \\
\text { Mobility }\end{array}$ \\
\hline Share adult pop. in parent. home & $\begin{array}{c}-0.215 \\
(0.046) * * *\end{array}$ & & & & & \\
\hline Respect parents & & $\begin{array}{c}-0.102 \\
(0.023)^{* * *}\end{array}$ & & & & \\
\hline Obedience & & & $\begin{array}{c}-0.057 \\
(0.027)^{* *}\end{array}$ & & & \\
\hline Make parents proud & & & & $\begin{array}{c}-0.056 \\
(0.013)^{* * *}\end{array}$ & & \\
\hline Parents responsibility & & & & & $\begin{array}{l}-0.049 \\
(0.037)\end{array}$ & \\
\hline Family important & & & & & & $\begin{array}{l}-0.061 \\
(0.036)\end{array}$ \\
\hline Observations & 28769 & 38479 & 29820 & 29820 & 36172 & 36425 \\
\hline & & CENSUS 19 & & & & \\
\hline & $\begin{array}{c}(1) \\
\text { Mobility }\end{array}$ & $\begin{array}{c}(2) \\
\text { Mobility }\end{array}$ & $\begin{array}{c}(3) \\
\text { Mobility }\end{array}$ & $\begin{array}{c}(4) \\
\text { Mobility }\end{array}$ & $\begin{array}{c}(5) \\
\text { Mobility }\end{array}$ & $\begin{array}{c}(6) \\
\text { Mobility }\end{array}$ \\
\hline Share adult pop. in parent. home & $\begin{array}{c}-0.212 \\
(0.026) * * *\end{array}$ & & & & & \\
\hline Respect parents & & $\begin{array}{c}-0.105 \\
(0.021)^{* * *}\end{array}$ & & & & \\
\hline Obedience & & & $\begin{array}{c}-0.083 \\
(0.028)^{* * *}\end{array}$ & & & \\
\hline Make parents proud & & & & $\begin{array}{c}-0.043 \\
(0.012)^{* * *}\end{array}$ & & \\
\hline Parents responsibility & & & & & $\begin{array}{l}-0.043 \\
(0.031)\end{array}$ & \\
\hline Family important & & & & & & $\begin{array}{l}-0.066 \\
(0.042)\end{array}$ \\
\hline Observations & 119293 & 146774 & 122212 & 122212 & 141176 & 142398 \\
\hline \multicolumn{7}{|c|}{ CENSUS 1970} \\
\hline & $\begin{array}{c}(1) \\
\text { Mobility }\end{array}$ & $\begin{array}{c}(2) \\
\text { Mobility }\end{array}$ & $\begin{array}{c}(3) \\
\text { Mobility }\end{array}$ & $\begin{array}{c}(4) \\
\text { Mobility }\end{array}$ & $\begin{array}{c}(5) \\
\text { Mobility }\end{array}$ & $\begin{array}{c}\text { (6) } \\
\text { Mobility }\end{array}$ \\
\hline Share adult pop. in parent. home & $\begin{array}{c}-0.197 \\
(0.022) * * *\end{array}$ & & & & & \\
\hline Respect parents & & $\begin{array}{c}-0.083 \\
(0.022)^{* * *}\end{array}$ & & & & \\
\hline Obedience & & & $\begin{array}{c}-0.079 \\
(0.024)^{* * *}\end{array}$ & & & \\
\hline
\end{tabular}


Make parents proud

Parents responsibility

Family important

Observations

Robust standard errors are clustered at the country

99260

120719

Each regression controls for a quadratic in age, education, marital status, gender, a dummy for being unemployed, personal income and state fixed effects.

\section{$-0.034$ \\ $(0.011)^{* * *}$}

$-0.037$

$(0.030)$

$-0.068$

$(0.038)^{*}$

117471

$101495 \quad 101495 \quad 116384$

ed, personal 
Table B21

Family Ties and Unemployment

Second Generation Immigrants, Census 1940, 1960 and 1970

CENSUS 1940

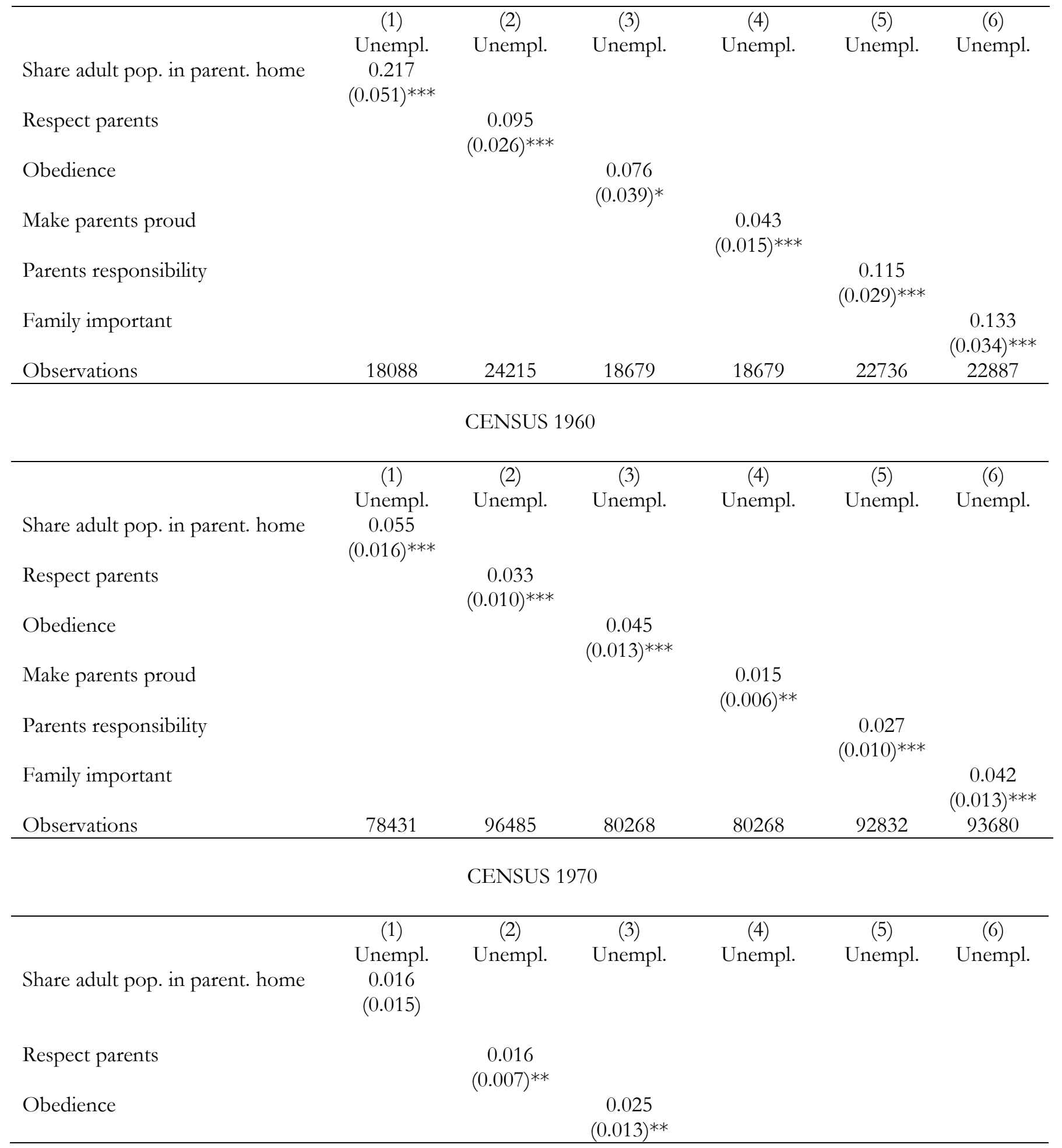


Make parents proud

Parents responsibility

Inherited family values (GSS)

Observations

67067

81816

68551

68551

78915

0.015

$(0.009)^{*}$

0.014

(0.012)

Robust standard errors are clustered at the country of origin level. $* * *$ significant at $1 \%$, ${ }^{*}$ significant at $5 \%, *$ significant at $10 \%$. Each regression controls for a quadratic in age, education, marital status, gender and state fixed effects. 
Table B22

Family Ties and Log Hourly Wages

Second Generation Immigrants, Census 1940, 1960 and 1970

CENSUS 1940

\begin{tabular}{|c|c|c|c|c|c|c|}
\hline & $\begin{array}{c}(1) \\
\text { Log wage } \\
\end{array}$ & $\begin{array}{c}(2) \\
\text { Log wage } \\
\end{array}$ & $\begin{array}{c}(3) \\
\text { Log wage }\end{array}$ & $\begin{array}{c}\text { (4) } \\
\text { Log wage } \\
\end{array}$ & $\begin{array}{c}\text { (5) } \\
\text { Log wage } \\
\end{array}$ & $\begin{array}{c}\text { (6) } \\
\text { Log wage }\end{array}$ \\
\hline Share adult pop. in parent. home & $\begin{array}{c}-0.617 \\
(0.237)^{* *}\end{array}$ & & & & & \\
\hline Respect parents & & $\begin{array}{c}-0.185 \\
(0.094)^{*}\end{array}$ & & & & \\
\hline Obedience & & & $\begin{array}{c}-0.236 \\
(0.105)^{* *}\end{array}$ & & & \\
\hline Make parents proud & & & & $\begin{array}{c}-0.120 \\
(0.047)^{* *}\end{array}$ & & \\
\hline Parents responsibility & & & & & $\begin{array}{l}-0.057 \\
(0.094)\end{array}$ & \\
\hline Family important & & & & & & $\begin{array}{l}-0.054 \\
(0.147)\end{array}$ \\
\hline Observations & 11718 & 15833 & 12106 & 12106 & 14833 & 14934 \\
\hline R-squared & 0.20 & 0.21 & 0.21 & 0.21 & 0.20 & 0.20 \\
\hline \multicolumn{7}{|c|}{ CENSUS 1960} \\
\hline & $\begin{array}{c}\text { (1) } \\
\text { Log wage }\end{array}$ & $\begin{array}{c}\text { (2) } \\
\text { Log wage }\end{array}$ & $\begin{array}{c}\text { (3) } \\
\text { Log wage }\end{array}$ & $\begin{array}{c}\text { (4) } \\
\text { Log wage }\end{array}$ & $\begin{array}{c}\text { (5) } \\
\text { Log wage }\end{array}$ & $\begin{array}{c}(6) \\
\text { Log wage }\end{array}$ \\
\hline Share adult pop. in parental home & $\begin{array}{c}-0.336 \\
(0.140)^{* *}\end{array}$ & & & & & \\
\hline Respect parents & & $\begin{array}{l}-0.075 \\
(0.070)\end{array}$ & & & & \\
\hline Obedience & & & $\begin{array}{l}-0.154 \\
(0.096)\end{array}$ & & & \\
\hline Make parents proud & & & & $\begin{array}{l}-0.050 \\
(0.037)\end{array}$ & & \\
\hline Parents' responsibility & & & & & $\begin{array}{l}-0.087 \\
(0.062)\end{array}$ & \\
\hline Family important & & & & & & $\begin{array}{l}-0.148 \\
(0.109)\end{array}$ \\
\hline Observations & 61028 & 75346 & 62409 & 62409 & 72408 & 73044 \\
\hline R-squared & 0.19 & 0.18 & 0.18 & 0.18 & 0.18 & 0.18 \\
\hline
\end{tabular}

CENSUS 1970

(1) (2) (3) (4) (5)

Log wage Log wage Log wage Log wage Log wage Log wage

Share adult pop. in parental home

$$
(0.134) * *
$$

$(0.134)^{* *}$

Respect parents

$-0.098$

$(0.082)$ 


\begin{tabular}{|c|c|c|c|c|c|c|}
\hline Obedience & & & $\begin{array}{c}-0.163 \\
(0.092)^{*}\end{array}$ & & & \\
\hline Make parents proud & & & & $\begin{array}{c}-0.064 \\
(0.035)^{*}\end{array}$ & & \\
\hline Parents' responsibility & & & & & $\begin{array}{c}-0.210 \\
(0.080)^{* *}\end{array}$ & \\
\hline Family important & & & & & & $\begin{array}{c}-0.261 \\
(0.131)^{*}\end{array}$ \\
\hline Observations & 56291 & 68766 & 57494 & 57494 & 66303 & 66931 \\
\hline R-squared & 0.21 & 0.21 & 0.21 & 0.21 & 0.21 & 0.21 \\
\hline
\end{tabular}

Table B23

Family Ties and Log Hourly Wages

Second Generation Immigrants, CPS 1994-2012

Sample restricted to second generation immigrants with parents from the same country of origin

\begin{tabular}{|c|c|c|c|c|c|c|}
\hline & $\begin{array}{c}\text { (1) } \\
\text { Log wage }\end{array}$ & $\begin{array}{c}\text { (2) } \\
\text { Log wage }\end{array}$ & $\begin{array}{c}\text { (3) } \\
\text { Log wage }\end{array}$ & $\begin{array}{c}\text { (4) } \\
\text { Log wage }\end{array}$ & $\begin{array}{c}\text { (5) } \\
\text { Log wage }\end{array}$ & $\begin{array}{c}(6) \\
\text { Log wage }\end{array}$ \\
\hline Share adult pop. in parent. home & $\begin{array}{c}-0.178^{*} \\
(0.100)\end{array}$ & & & & & \\
\hline Respect parents & & $\begin{array}{c}-0.308^{* * *} \\
(0.110)\end{array}$ & & & & \\
\hline Obedience & & & $\begin{array}{c}-0.239 * * * \\
(0.079)\end{array}$ & & & \\
\hline Make parents proud & & & & $\begin{array}{c}-0.103^{* * *} \\
(0.025)\end{array}$ & & \\
\hline Parents responsibility & & & & & $\begin{array}{c}-0.169 * * * \\
(0.064)\end{array}$ & \\
\hline Family important & & & & & & $\begin{array}{c}-0.288^{* * *} \\
(0.108)\end{array}$ \\
\hline Observations & 35167 & 43222 & 35447 & 35398 & 43226 & 43248 \\
\hline R-squared & 0.28 & 0.28 & 0.28 & 0.28 & 0.28 & 0.28 \\
\hline
\end{tabular}




\section{Table B24}

Family Ties and Mobility

Second Generation Immigrants, CPS 1994-2012

Sample restricted to second generation immigrants with parents from the same country of origin

\begin{tabular}{|c|c|c|c|c|c|c|}
\hline & $\begin{array}{c}(1) \\
\text { Mobility }\end{array}$ & $\begin{array}{c}(2) \\
\text { Mobility } \\
\end{array}$ & $\begin{array}{c}(3) \\
\text { Mobility }\end{array}$ & $\begin{array}{c}(4) \\
\text { Mobility }\end{array}$ & $\begin{array}{c}(5) \\
\text { Mobility } \\
\end{array}$ & $\begin{array}{c}\text { (6) } \\
\text { Mobility }\end{array}$ \\
\hline Share adult pop. in parent. home & $\begin{array}{c}-0.128^{* * *} \\
(0.032)\end{array}$ & & & & & \\
\hline Respect parents & & $\begin{array}{c}-0.080^{* *} \\
(0.039)\end{array}$ & & & & \\
\hline Obedience & & & $\begin{array}{c}-0.070^{* * *} \\
(0.023)\end{array}$ & & & \\
\hline Parents proud & & & & $\begin{array}{c}-0.026^{*} \\
(0.013)\end{array}$ & & \\
\hline Parents responsibility & & & & & $\begin{array}{c}-0.035^{*} \\
(0.021)\end{array}$ & \\
\hline Family important & & & & & & $\begin{array}{l}-0.059 \\
(0.042)\end{array}$ \\
\hline Observations & 54334 & 66506 & 54726 & 54614 & 66466 & 66528 \\
\hline
\end{tabular}

Table B25

Family Ties and Unemployment

Second Generation Immigrants, CPS 1994-2012

Sample restricted to second generation immigrants with parents from the same country of origin

\begin{tabular}{|c|c|c|c|c|c|c|}
\hline & $\begin{array}{c}(1) \\
\text { Unempl. }\end{array}$ & $\begin{array}{c}(2) \\
\text { Unempl. }\end{array}$ & $\begin{array}{c}(3) \\
\text { Unempl. }\end{array}$ & $\begin{array}{c}(4) \\
\text { Unempl. }\end{array}$ & $\begin{array}{c}\text { (5) } \\
\text { Unempl. }\end{array}$ & $\begin{array}{c}\text { (6) } \\
\text { Unempl. }\end{array}$ \\
\hline Share adult pop. in parent. home & $\begin{array}{c}0.029 \\
(0.035)\end{array}$ & & & & & \\
\hline Respect parents & & $\begin{array}{c}0.103^{* * *} \\
(0.019)\end{array}$ & & & & \\
\hline Obedience & & & $\begin{array}{c}0.066^{* * *} \\
(0.018)\end{array}$ & & & \\
\hline Make parents proud & & & & $\begin{array}{c}0.033 * * * \\
(0.007)\end{array}$ & & \\
\hline Parents responsibility & & & & & $\begin{array}{c}0.067^{* * *} \\
(0.013)\end{array}$ & \\
\hline Family important & & & & & & $\begin{array}{c}0.104^{* * *} \\
(0.024)\end{array}$ \\
\hline Observations & 32755 & 40295 & 33008 & 32952 & 40286 & 40310 \\
\hline
\end{tabular}




\section{Table B26}

Correlation between the GSS measure of family values and the WVS measure, GSS 1972-2010

(1)

Frequency of contacts with relatives $0.589 * * *$

\section{$(0.149)$}

Respect parents

Obedience

Parents proud

Parents responsibility

Family important

Observations

0.04

\begin{tabular}{l}
\multicolumn{2}{c}{$\begin{array}{c}0.131 * * * \\
(0.042)\end{array}$} \\
\\
\end{tabular}

(2)

(4)

(5)

(6)

Frequency of contacts with

Frequency of contacts with

Frequency of contacts with relatives relatives

Frequency of contacts with relatives

Frequency of contacts with relatives

$$
0.388 * * *
$$

(0.124) 
Figure 3bis

Family Ties and Employment Protection in OECD countries (regular and temporary contracts)
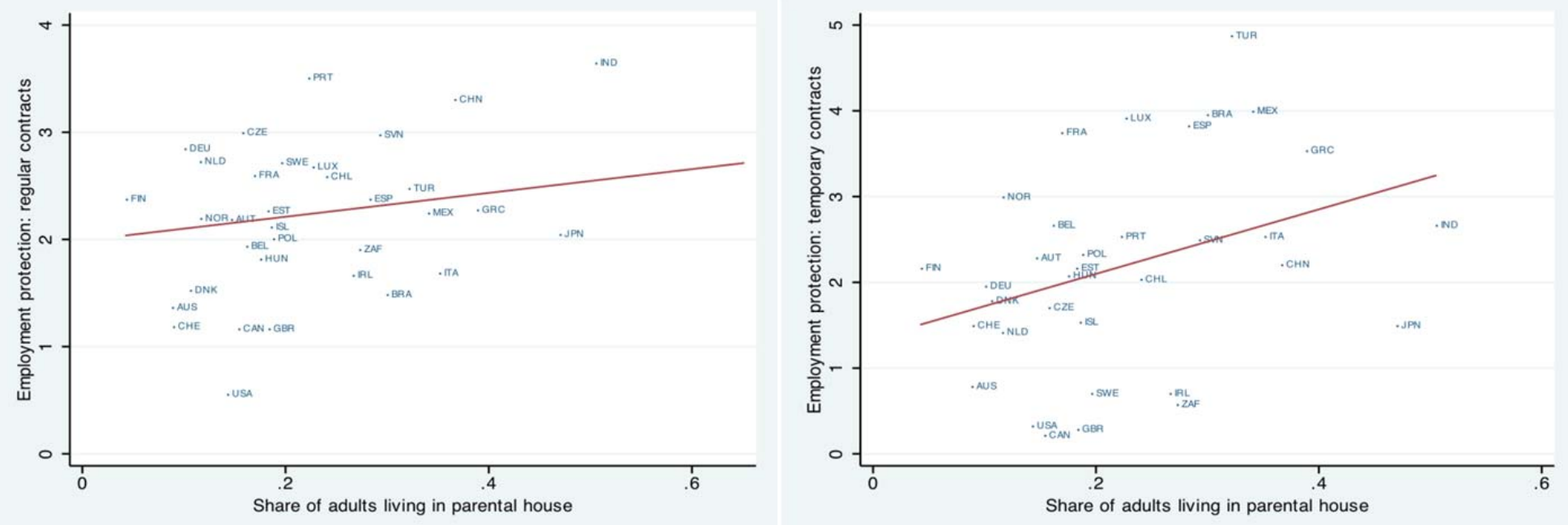

Source: WVS 1980-2000 and OECD (2008) 
Figure 8

Family Types in Europe (Todd classification)

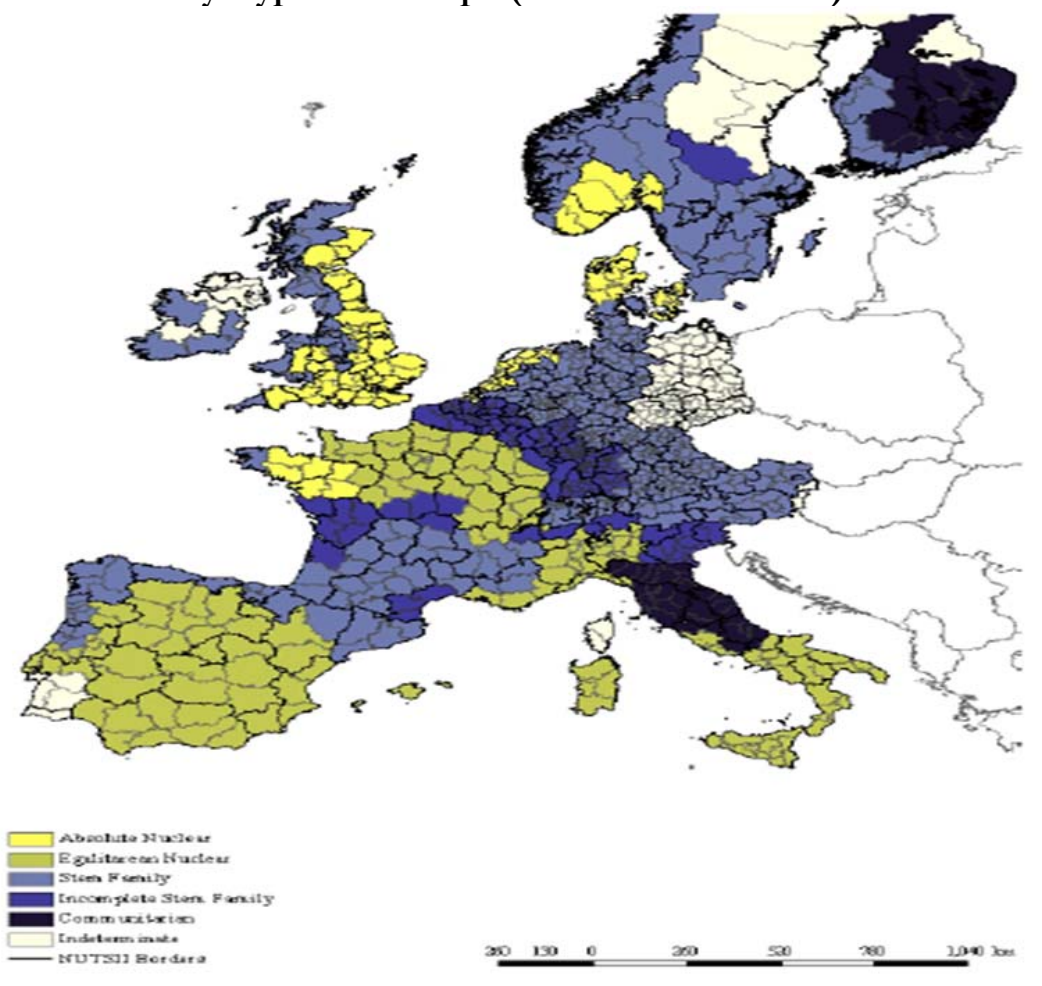

